\title{
Improving Patient and Provider Communication: A Synthesis and Review of Communication Interventions
}

\author{
Lynda A. Anderson ${ }^{\mathrm{a}, \mathrm{b}}, \mathrm{PhD}$ and Patricia A. Sharpe ${ }^{\mathrm{a}}$, MPH \\ "Department of Health Behavior and Health Education, School of Public Health, University of Michigan, Ann Arbor, Michigan and \\ ${ }^{b}$ Geriatric Research, Education and Clinical Center, VAMC, Ann Arbor, Michigan (USA)
}

(Received February 28th, 1990)

(Accepted October 5th 1990)

\begin{abstract}
Results of 40 experimental trials designed to enhance communication skills of patients or health-care providers are summarized. Calculation of effect sizes (ES) offered a method for comparing the impact of these interventions on communicative behaviors. Communicative behaviors were categorized into interpersonal processes and interviewing skills. For patienttargeted interventions that examined interpersonal process variables $(n=10)$, modeling and skill-practice interventions exhibited the largest $E S$ values. For provider-targeted interventions $(n=30), 21$ assessed interviewing skills, 5 examined interpersonal processes and 4 examined both categories. Effect sizes were moderate to large for interviewing skills interventions targeted at medical students. For other provider groups, the majority of studies failed to include the necessary data to calculate ES. The dearth of studies examining interpersonal processes prevented drawing any conclusive statements about their relative efficacy. On the basis of these findings, current methodological concerns are described, recommendations for future research presented and practical implications discussed.
\end{abstract}

Keywords: Physician-patient relations; Communication; Meta-analysis; Patient participation.

\section{Introduction}

Since the mid-1960s, the growth of published studies on patient-provider communication has increased exponentially. Clinicians and researchers are becoming progressively more aware of the importance of communication on patient-care outcomes. Several excellent reviews of descriptive studies of patient-provider communication and its relationship to patient-care outcomes are available in the published literature (see [1,2] for the most recent reviews).

Although previous reviews include some intervention studies in their synopsis, their focus is on the relationship between communicative behaviors and patient outcomes rather than the effects of interventions on communication behavior. If patient educators are to have an impact on patient-provider communication, there is a pressing need to understand the methods and results of empirical studies of interventions applied to patient-provider communication across diverse disciplines. The present 
review is designed to fill this gap in the literature.

This review is undertaken with four major objectives: (a) to provide a review of intervention studies designed to enhance the communicative skills of health-care providers and/or patients; (b) to address similarities and differences in methodologies, strategies and outcomes of these investigations; (c) to contrast and summarize interventions targeted at various communicative behaviors; (d) to suggest guidelines for future research and discuss implications for practice.

\section{Methods}

The research proceeded in three stages: (1) development of criteria for inclusion and literature search; (2) coding of study attributes; (3) calculation of effect sizes and data analysis.

\section{Criteria for inclusion and search procedures}

Studies included in this review met the following criteria: (a) examined an intervention designed to facilitate verbal or nonverbal communication; (b) targeted the intervention toward modifying the communicative behaviors of health-care providers and/or patients; (c) included a control or comparison group; (d) presented quantitative findings regarding verbal or nonverbal communicative behaviors; (e) focused on medical encounters that were not strictly psychotherapeutic; (f) published in English.

Studies assessing communicative behaviors through indirect methods such as medical record reviews, case reports, paper and pencil tests, or self-reports from subjects were excluded. Although such studies provide interesting results, they were excluded bccause there has been little empirical evidence to date that these indirect methods represent veritable communicative behaviors. In addition, studies using single-group, pretest-posttest designs were excluded. Kraemer and Andrews demonstrated that the effect of a single group, pretest-posttest design is only equal to that of an experimental- control design "if one has prior certainty of the absence of time effects and of placebo effects" [3, p. 407]. Several studies examined in the current review revealed that time effects do occur in this line of research. Moreover, Oetting [4] forewarned that control groups are essential in scientific inquiries when the purpose is to understand why something has occurred rather than simply to document that something has occurred. References for single-group, pretest-posttest designs are available upon request from the first author.

The studies in this review were identified according to the following procedures: (a) Medline on-line database search (using the key terms physician-patient relations, patient participation, patient education, communication, medical history taking); (b) hand searches of Academic Medicine (formerly the Journal of Medical Education) and Medical Education (formerly the British Journal of Medical Education); (c) Psychological Abstracts database search (key term therapeutic processes). Combinations of key words were also used and no exclusion was made on year of publication. Additional sources included the reference lists of all articles found by the above procedures.

\section{Coding of study attributes}

A total of 40 articles describing 45 studies met the initial inclusion criteria. Whenever the same study was described in more than one article, the results were merged, bringing the total number of eligible studies to 42 . Each of the authors reviewed all studies independently using a standard format that assessed study design, sample characteristics, intervention strategy, dependent variables and measures, and major findings. During this process two other studies were climinated because the nature of the intervention could not be determined [5] (i.e., the intervention was not described) or the researchers confounded the communicative behaviors of trainers with study participants [6]. Thus, 40 studies are described in this review. Interrater agreement was calculated for all key components of the rating scale. Using the 
Table 1. Methodological quality rating.

\section{Design of study/assignment}

Experimental, random assignment (1 point)

Quasi-experimental design (0 points)

2. Selection and specification of study sample

Random sample of all subjects from a specified population ( 1 point)

Convenience sample or nonspecified sample ( 0 points)

3. Sample size

An $n$ per group sufficient to detect a significant effect $(P<0.05)$ with a power of 0.80 or reported calculation of power (1 point)

An $n$ per group insufficient to detect a significant effect $(P<0.05)$ with a power of 0.80 or no reported calculation of power ( 0 points)

4. Coder reliability (determined by assessment and reports of interrater and/or intrarater reliability based on data from the current study)

Reliability greater than or equal to 0.80 ( 1 point)

Reliability less than or equal to 0.79 ( 0 points)

5. Specification and use of blinding for interaction analysis

Coders were blinded ( 1 point)

Coders were not blinded or not reported ( 0 points)

chance-corrected kappa coefficient [7], interrater agreement prior to consensus was good, $k$ ranged from 0.72 to 1 (complete agreement). Data reported herein were established by final consensus of the authors.

Ratings of methodological quality. As recommended by Glass et al. [8], we included all studies regardless of their quality and later rated their level of quality, thereby eliminating the potential for bias. A rating system based on prior meta-analysis [9] was devised for use in this study (see Table 1). Ratings (up to a maximum of five points) were awarded to each study depending on how well it addressed issues related to internal and external validity. Ratings were established by consensus of the authors.

Types of interventions. Various types of interventions were represented by these studies. Based on criteria suggested in the literature [10], interventions were classified hierarchically into one of four groups: (a) instruction; (b) feedback; (c) modeling; (d) skill practice. When a study included multiple strategies, the most powerful technique was used to group the intervention. Note that interventions were classified as to their source of influence (e.g., instruction and modeling) rather than their mode of presentation (e.g., live or videotaped presentations) $[10,11]$.

Interventions categorized as instruction employed strategies based on oral or written persuasion [12-15]. Methods of presentation included videotaped lectures, self-instruction and face-to-face didactic sessions aimed at facilitating the communicative behaviors of participants. In one case, the intervention focused on teaching about disease processes rather than communication skills [15].

Interventions categorized as feedback involved strategies that provided detailed assessment/evaluation of the participant's performance related to the medical interview [16-22]. Methods of presentation included oral or written critiques of an interview by oneself or others (e.g., trainer). Feedback was most often used alone but was sometimes supplemented with instruction (i.e., lectures or readings). Interventions categorized as feedback did not include modeling or skill practice as a definitive element of the program.

Interventions categorized as modeling employed strategies based on an extensive research literature that indicates that exposing 
an individual to a model that depicts the behavior of interest can affect the observer's behavior in a positive manner [11]. Modeling displays are most often created by human actors (models) who perform various behaviors embodying a certain principle or rule. Observation of a model can provide knowledge of what to do as well as a concrete example of how to do it. Modeling strategies were sometimes used alone but were often combined with instruction and/or feedback [23-28].

Interventions categorized as skill practice involved participants actually producing the behavior(s) of interest [29-46]. Skill practice included one or more of the following: initiation of the behavior, monitoring and skill refinements based on repeated practice. Skill practice is considered a powerful means of intervention because it provides information based on actual accomplishments and allows for skill refinements [10]. Programs focused on skill practice frequently included didactic instruction, multiple feedback sessions and, on occasion, modeling.

Conceptual groupings of communicative behaviors. Communicative behaviors were categorized into two broad categories: (a) interpersonal processes; (b) interviewing skills. The first major category of communication, interpersonal processes, refers to the linguistic and paralinguistic elements of communication. Within the domain of interpersonal processes, language use and speech patterns are examined in order to describe how communication may reflect underlying social relationships [47]. Commonly known as discourse analysis, these interaction analysis systems have largely developed from the social science literature. Studies may examine both patient and provider communicative behaviors. Communicative behavior is often analyzed at the level of the utterance (i.e., individual speech acts) and generally reported in terms of its frequency of occurrence. Communicative behaviors are generally classified into a priori categories, such as task-oriented behaviors (e.g., disclosure) or socioemotional behaviors (e.g., empathy) [1].
The second major category of communication focuses on interviewing skills. The medical interview is viewed as an important means of reaching a diagnosis and initiating appropriate treatment [48]. It enables the clinician to elicit information about the onset, severity and course of the patient's problems and determine the contribution of psychological and social factors. Similarly, during the medical interview a patient can gain a better understanding of his/her problem and obtain recommendations to alleviate or control the problem. Numerous coding systems are designed to examine interviewing skills and offer a means by which such skills can be taught and evaluated. These studies examine two subcategories of interviewing skills: content and technique.

Interviewing skills related to content refer to the ability to gather, synthesize and provide information during a clinical interview [48]. Content pertains to the data acquired and provided by all parties during the clinical interview, including providers, patients and their companions. However, content-oriented analysis systems have tended to focus only on the behavior of the clinician. Definitions appearing in the literature reflect this fact. Information gathering, or data collection, concerns the medical and psychosocial information gathered during the medical history and/or physical examination. Information giving refers to feedback to the patient in the form of education and counseling. Content of the interview is usually reported in terms of the amount of data obtained (i.e., percentage of relevant data solicited from a patient) or ratings of the clinician's ability to gather information during the medical interview.

The second category of interviewing skills, technique, focuses on the competency of the provider to conduct and manage an interview. These skills are believed to form the foundation for a therapeutic relationship [48]. Generally, techniques used in the medical interview are rated with a checklist of competency-based skills. Although the checklists vary in terms of specific skill components, they usually include 
the following basic elements: opening and closing an interview; the use of open-ended versus closed-ended questions; listening skills; nonleading questions; transitional statements and/or behaviors that connote the establishment of rapport [49]. Interviewing technique is most often evaluated by trained observers and reported as frequency counts (e.g., presence or absence of a specific skill) or as ratings of various interviewing skills.

Calculation of effect size. For every study that provided the necessary data, effect size was calculated for each subcategory of communicative behavior using Cohen's $d$ [50]. An effect size is used to describe "the degree to which the phenomenon is present in the population" [50, p. 9]. Cohen's $d$ was calculated by dividing the difference between the mean experimental and control groups posttest scores by the pooled (within) standard deviation of the two scores [50]. For studies that did not provide the requisite means and standard deviations, effect sizes were calculated by transforming $t-, F$ - and chi-square statistics [51]. The sign of effect size was set according to the direction of the outcome, with a positive effect size connoting positive outcome and a negative sign before the effect size denoting a negative outcome for the experimental group compared to the control/comparison group. Cohen [50] provides the following guidelines for interpreting effect size: $d=0.20$ (small effect), $d=0.50$ (medium effect) and $d=0.80$ (large effect). For studies that compared more than two experimental conditions (or did not employ a true control or placebo control group), the theoretically most powerful intervention was compared to the least powerful intervention.

Once effect sizes were calculated for individual studies, a test for homogeneity [51] was performed to determine the appropriateness of synthesizing a subgroup of studies. The test for homogeneity of effect sizes $(H)$ is interpreted as a chi-square distribution with $n-1$ degrees of freedom [51]. Significant heterogeneity among effect sizes was indicated when $P$ was less than 0.05 . When effect sizes were deemed to be homogeneous, a mean effect size for the subgroup was calculated and a confidence interval was constructed to assist with interpretation.

\section{Results}

\section{Description of studies}

Appendices $A-D$ provide a detailed description of each investigation. Studies are grouped according to the type and target of intervention. In the following sections we briefly describe the studies detailed in the appendices. Major issues summarized are: (a) study design; (b) sample characteristics; (c) types of intervention; (d) outcomes.

Study design. A total of 35 studies reported data from a primary study (immediate posttest) and 5 studies were designed to assess the longterm impact of the intervention (herein referred to as behavioral retention studies). Among studies labeled primary investigations, randomization procedures for assigning subjects to treatment conditions were employed in $80 \%$ of the studies directed at patient populations and $56 \%$ of studies targeted at providers. Quasiexperimental designs were used most frequently in interventions conducted during clerkship and residency rotations. Among behavioral retention studies, three of the five used randomized control designs.

Sample. Twenty-five percent of the studies $(n=10)$ involved interventions directed at patients and $75 \%(n=30)$ were directed at providers. In the behavioral retention studies, medical students were followed into their clerkships [16 (three studies are reported)] or residencies/internships [44 45$]$.

Column 2 in each appendix provides a descriptive profile of study participants. There were three particularly noteworthy characteristics of these samples. First, there were sizable differences in the mean number of subjects by both type and target of intervention. Sample sizes in patient-directed interventions were, on average, about twice that of provider-directed 
interventions $(n=10$, mean $=96.3(\mathrm{SD}=55))$ for patient-directed interventions and $n=30$, mean $49.8(\mathrm{SD}=55)$ for provider-directed interventions).

Second, considerable variation was found in the thoroughness with which the sample characteristics were reported. Most studies directed at patients supplied information on two or more of the attributes of the study samples. Mean age of the samples ranged from 28 to 58 years. The gender composition of the samples also varied, with about half favoring women and half men. Among provider interventions, one study described the demographic characteristics of the participants and interactants [43].

A third distinct characteristic of these investigations was the use of simulated interactants. Among provider interventions, 19 studies assessed providers' communicative skills in interactions with simulated patients, who were trained to play the role of a patient. In seven of these studies, simulated patients also served as trainers and provided fcedback regarding providers' interviewing skills [16 (four studies), 17,19,40]. Among patient interventions, Wallston et al. [23] used a research assistant trained to play the role of a nurse.

In summary, investigators of patient-directed interventions were better at providing information on their study samples than were providerdirected studies. Nevertheless, most investigators were not very conscientious in describing the characteristics of the interactants.

Types of intervention. As shown in Table 2, five studies were classified as instruction. All instructional interventions involved a single training session completed prior to the clinic visit (see Appendix A for details).

Feedback interventions were targeted solely at health-care providers. As indicated in Table 2 , three studies used only a single feedback session. In the seven remaining studies, feedback was supplemented by instruction. Length of training was reported in only four studies, vary-
Table 2. Frequency of single versus multiple component $^{a}$ interventions by type and target of intervention.

\begin{tabular}{llll}
\hline $\begin{array}{l}\text { Type of } \\
\text { intervention }\end{array}$ & $\begin{array}{l}\text { Target of } \\
\text { intervention }\end{array}$ & $\begin{array}{l}\text { Single } \\
\text { component } \\
\text { program }\end{array}$ & $\begin{array}{l}\text { Multiple } \\
\text { component } \\
\text { program }\end{array}$ \\
\hline Instruction & Patients & 4 & 0 \\
& Providers & 1 & 0 \\
Feedback & Patients & 0 & 0 \\
& Providers & 3 & 7 \\
Modeling & Patients & 1 & 1 \\
& Providers & 0 & 4 \\
Skill & Patients & 0 & 4 \\
practice & Providers & 0 & 15
\end{tabular}

${ }^{a}$ Component refers to the number of different types of intervention strategies that were combined within a single treatment program (e.g., instruction plus modeling).

ing between 1.5 and $4 \mathrm{~h}$ (see Appendix B for complete details).

Among interventions grouped as modeling, two were directed at patients and four at providers. One study employed modeling alone, two combined modeling with instruction, one used feedback and two included instruction and feedback. Training time was reported in three studies; implementation time ranged from 13 min to $15 \mathrm{~h}$ (refer to Appendix C).

As revealed in Table 2, skill practice was the most frequently employed intervention. This broad category incorporated multiple strategies. All but one study included instruction, nine incorporated all types of strategies but modeling and nine others included all other intervention strategies. Training time was reported in seven studies, with implementation time ranging between $20 \mathrm{~min}$ and $30 \mathrm{~h}$ (see Appendix D).

Outcomes: communicative behaviors. Table 3 provides a descriptive summary of the types of communicative behaviors examined, sorted by target of intervention. In addition, a listing of the interaction analysis systems employed and 
Table 3. Summary and classification of interaction analysis systems (IAS) and coding reliabilities by type of communicative category and target group.

\begin{tabular}{|c|c|c|c|}
\hline \multirow{2}{*}{$\begin{array}{l}\text { COMMUNICATIVE } \\
\text { BEHAVIOR } \\
\text { Category }^{a}\end{array}$} & \multicolumn{2}{|c|}{ Target group } & \multirow[t]{2}{*}{ Reference for systems used } \\
\hline & $\begin{array}{l}\text { Patient } \\
\text { (frequency) }\end{array}$ & $\begin{array}{l}\text { Provider } \\
\text { (frequency) }\end{array}$ & \\
\hline \multicolumn{4}{|c|}{$\begin{array}{l}\text { INTERPERSONAL PROCESSES } \\
\text { Task-oriented behaviors }\end{array}$} \\
\hline \multicolumn{4}{|c|}{ Interactional analysis systems ${ }^{\mathrm{b}}$} \\
\hline Standardized system & 5 & 2 & $52,53,54$ \\
\hline Modified system & 2 & - & 54,55 \\
\hline Unique & 3 & - & - \\
\hline \multicolumn{4}{|l|}{ Reliabilities $^{\mathrm{c}}$} \\
\hline$\geq 0.80$ & 6 & 1 & \\
\hline$\leq 0.79$ & 1 & - & \\
\hline Not reported & 3 & 1 & \\
\hline \multicolumn{4}{|c|}{ Socioemotional behaviors } \\
\hline \multicolumn{4}{|c|}{ Interactional analysis systems $\mathrm{s}^{\mathrm{b}}$} \\
\hline Standardized system & - & 6 & $33,56-59$ \\
\hline Modified system & 1 & 1 & 55,60 \\
\hline Unique & - & - & - \\
\hline \multicolumn{4}{|l|}{ Reliabilities $^{\mathfrak{c}}$} \\
\hline$\geq 0.80$ & - & 4 & \\
\hline$\leq 0.79$ & 1 & 3 & \\
\hline Not reported & - & - & \\
\hline \multicolumn{4}{|c|}{ INTERVIEWING SKILLS } \\
\hline \multicolumn{4}{|c|}{ Content } \\
\hline \multicolumn{4}{|c|}{ Interactional analysis systems ${ }^{b}$} \\
\hline Standardized system & - & 10 & $17,33,56,61,62$ \\
\hline Modified system & - & 3 & 17,63 \\
\hline Unique & - & 1 & - \\
\hline \multicolumn{4}{|l|}{ Reliabilities $^{\mathfrak{c}}$} \\
\hline$\geq 0.80$ & - & 10 & \\
\hline$\leq 0.79$ & - & 1 & \\
\hline Not reported & - & 3 & \\
\hline \multicolumn{4}{|c|}{ Technique } \\
\hline \multicolumn{4}{|c|}{ Interactional analysis systems $\mathbf{s}^{\mathrm{b}}$} \\
\hline Standardized system & - & 14 & $17,33,56,61-65$ \\
\hline Modified system & - & 7 & $17,33,62,66$ \\
\hline Unique & - & 4 & - \\
\hline \multicolumn{4}{|l|}{ Reliabilities $^{c}$} \\
\hline$\geq 0.80$ & - & 18 & \\
\hline$\leq 0.79$ & - & 1 & \\
\hline Not reported & - & 6 & \\
\hline
\end{tabular}

${ }^{a}$ Categories are not mutually exclusive.

bStandardized refers to established IAS, modified refers to adapted IAS, and unique refers to studies that developed an IAS for use in the current study.

${ }^{\mathrm{c}}$ Reliability was determined by reports of interrater/intrarater reliability for the current study. 
interrater reliabilities for coding communicative behaviors are reported.

Regarding interpersonal processes, all 10 patient-directed studies were classified into interpersonal processes categories whereas only nine provider-directed studies involved communicative behaviors in this domain. Standardized interaction analysis systems were most frequently employed, including nine different interaction systems. Overall, $55 \%$ of the reported interrater reliabilities were greater than 0.80 .

Among those studies that targeted their interventions at interviewing skills, all were provider-directed interventions. The most frequently employed systems were developed by Stillman et al. [17], Maguire et al. [33] and Helfer et al. [63]. Nevertheless, there was considerable variation in use of different analysis systems because many investigators altered standardized systems for their study. Refer to Table 3 for specific data concerning content and technique categories.

\section{Effect size}

Although it would be desirable to compare the relative efficacy of different types of interventions, we determined that such an analysis was inappropriate for several reasons. Firstly, many researchers used combinations of various intervention strategies rather than a single type of intervention strategy, with only nine using a single-component intervention. Secondly, 11 studies failed to provide minimal data with which to calculate effect sizes. This occurred primarily among interventions targeted at residents and community-based physicians, which necessitated conducting separate analyses by target groups. Finally, many of the studies included multiple dependent variables, which when combined into a single meta-analysis would inflate the Type I error rate [51]. Thus, comparisons of different types of interventions were not possible.

To overcome these limitations, we followed the recommendations of Kulik [67] and Rosenthal [68] and examined subcategories of com- municative behaviors by specific target groups. Morcover, wc only calculated a mean effect size when the subgroup was determined to be homogeneous.

Effect sizes (ES) comparing the treatment to the control/comparison group are presented in Table 4 . When comparing results across studies, the following should be kept in mind: types of interventions being compared, type of interactants, study design and quality rating. Studies are divided into three main groups: interpersonal processes, interviewing skills and behavioral retention studies.

Interpersonal processes. All 10 patient intervention studies examined various types of interpersonal processes whereas only 9 out of 30 provider intervention studies assessed interpersonal processes. Patient interventions had a mean quality rating of 2.2 , ranging from 0 to 3. Among provider interventions, mean quality rating was 2 and varied between 0 and 3 .

Patient-directed interventions were organized together as the first major subgroup of studies in Table 4 . Task-oriented behaviors are behaviors involved in the exchange of information such as question-asking, informationseeking and latency (the number of seconds until the patients' first bid for clarification). Socioemotional behaviors are categorized together as anger and affect.

For question-asking behavior, ES values were homogeneous $(H=4.37,6 \mathrm{df}, P>0.05)$, ranging between 0.28 and 0.68 . The mean ES was $0.44(\mathrm{SD}=0.17)$, with a $95 \%$ confidence interval of +0.32 to +0.56 . Overall, this group of interventions had a significant and moderate effect on question-asking behavior. For information-seeking, the ES values from four studies were homogeneous $(H=3.45,3 \mathrm{df}, P$ $>0.05$ ), ranging from 0.32 to 1.00 . The mean ES was $0.60(S D=0.29)$, with a $95 \%$ confidence interval of +0.32 to +0.88 . The ES values for latency of patients' first bid for information were not homogeneous (see Table 4 ). Effect size values were 0.46 and $1.66[23,24]$, respectively. For patient disclosive behavior, which 


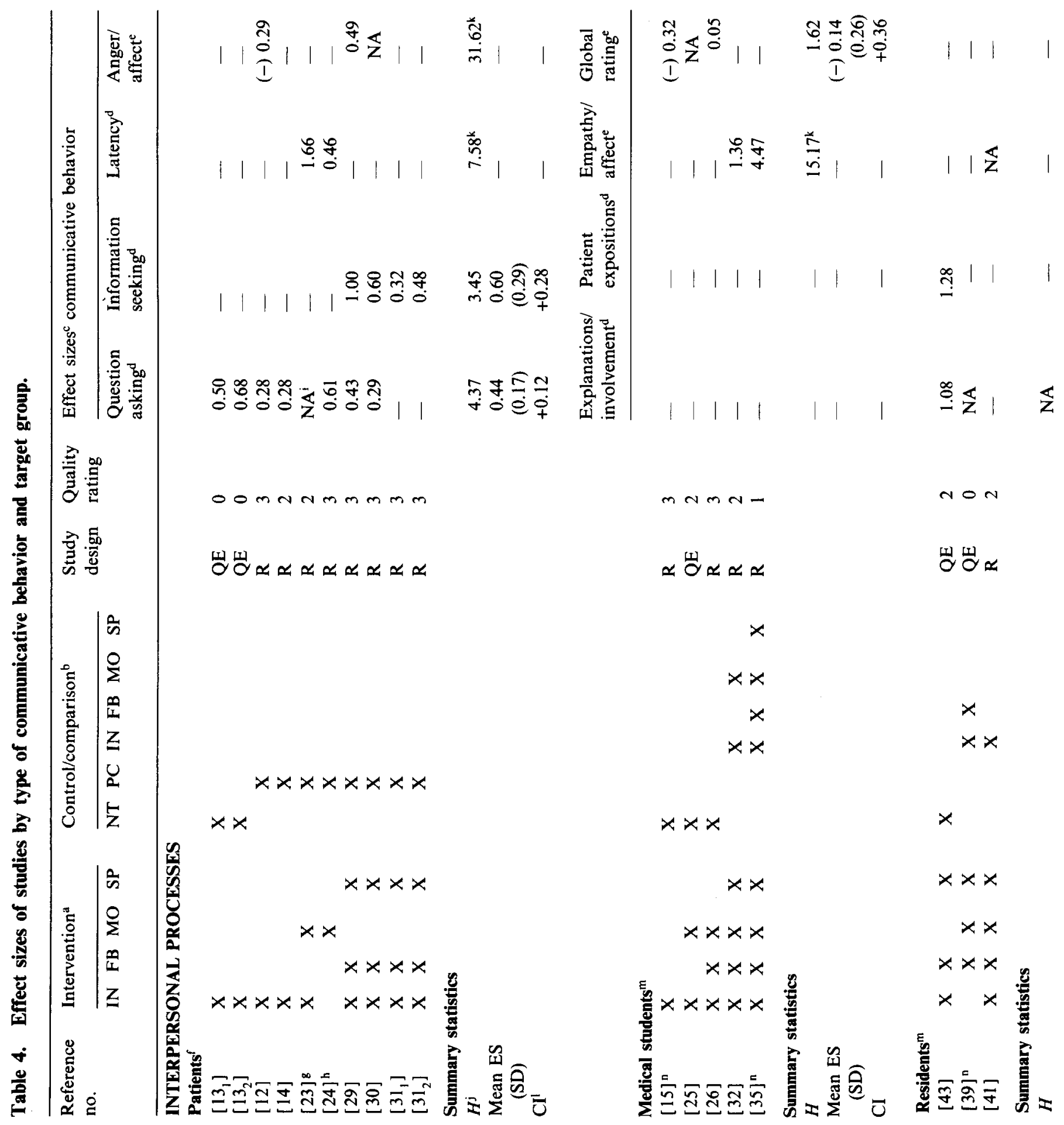




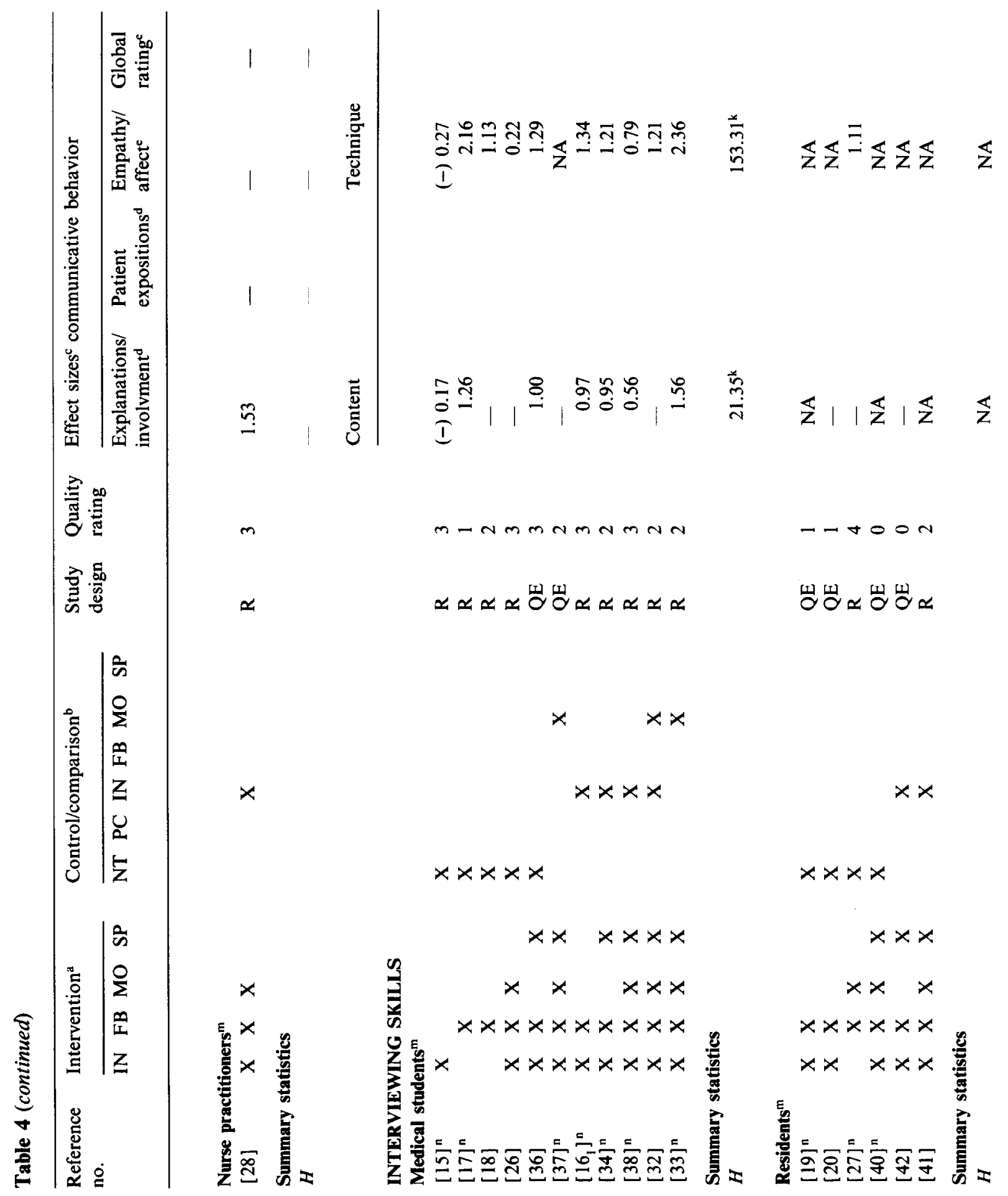




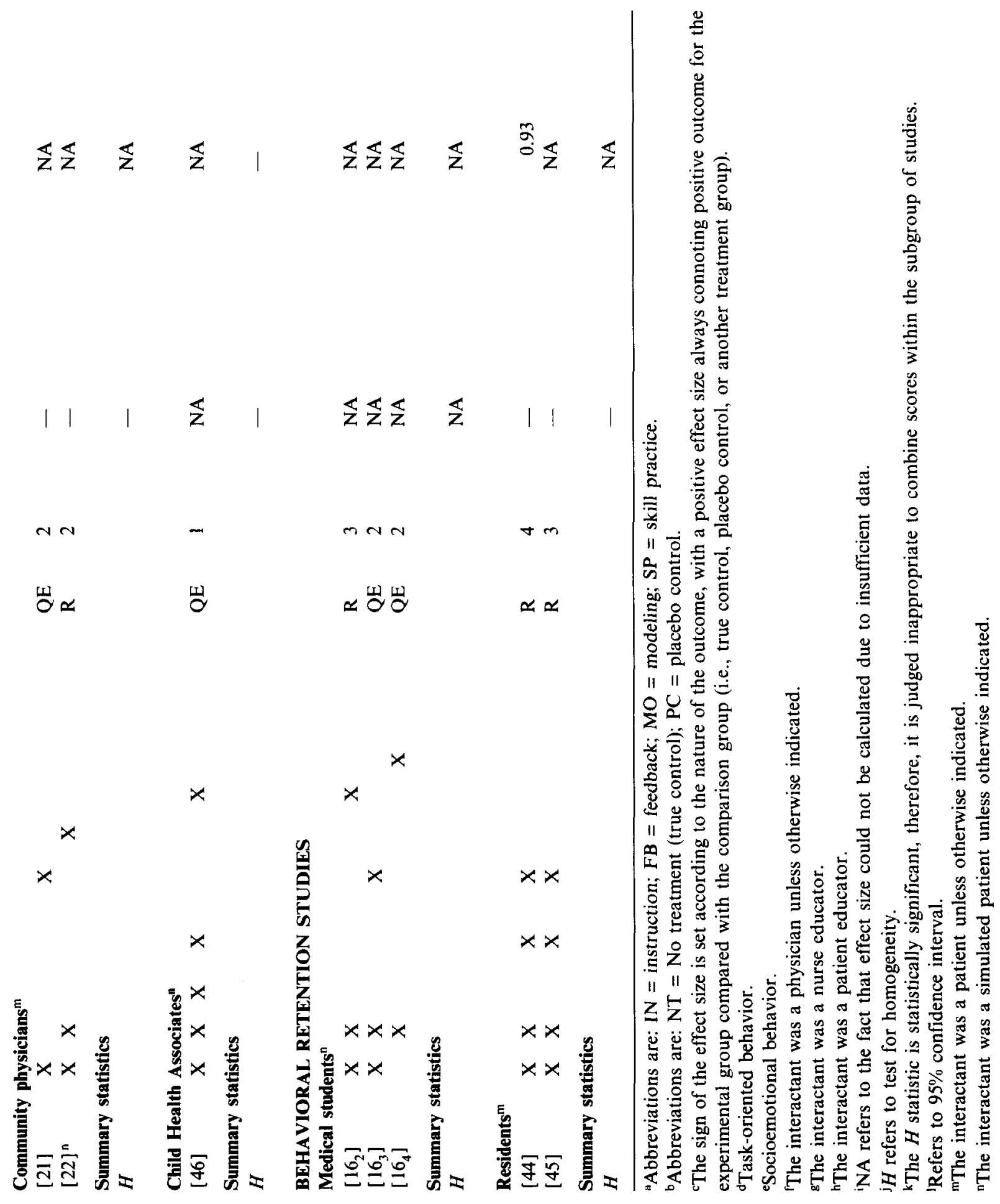


is not reported in Table 4, ES was 0.57 [24].

Turning to patients' socioemotional behaviors, ES values for patient anger and affect were not homogeneous. One study provided data with which to calculate ES for affect [29], which was 0.49. The ES for patient anger was -0.29 [12], indicating that patients in the placebo-control group expressed less anger compared to the experimental group.

In summary, among studies that received a quality rating of 2 or greater, the smallest ES values were found for instructional interventions that assessed question-asking behavior [12-14]. The largest ES values were found among modeling interventions that examined question-asking behaviors and/or latency [23-24] as well as skill practice interventions that examined information-seeking behaviors [29-31].

Provider interventions assessing interpersonal process variables are the next major subgroup of studies in Table 4 . Effect size values for taskoriented behaviors are listed in the first two columns. This includes provider explanations/involvement and patient expositions (i.e., patients talking about their concerns using their own words). The second two columns include the ES values for socioemotional behaviors (empathy/affect and global ratings). Three studies examined explanations/involvement variables $[39,43,28]$, with one study also assessing patient expositions [43]. Homogeneity could not be assessed due to the small number of studies and/or missing data. Effect sizes ranged from 1.08 to 1.53 .

For providers' socioemotional behaviors, ES values could be calculated for two of three studies but they were not homogeneous. Effect sizes were 1.36 and $4.47[32,35]$, respectively. For global ratings, ES values that could be calculated were negative $(-0.32)[15]$ or small $(0.05)$ [26]. In the case of the former [15], the intervention focused on teaching about disease processes rather than communication skills.

The dearth of studies examining any given behavior and the wide variability of the types of provider-targeted interventions prevents drawing conclusive statements about the relative efficacy of these interventions on interpersonal processes.

Interviewing skills. Effect sizes for content and technique skills are also presented in Table 4 . A total of 20 primary investigations examined interviewing skills. All of these studies were targeted at health care providers, with four also involving interpersonal process variables $[15,26,32,41]$.

Interventions targeted at community physicians and child health associates had mean quality ratings of 2 and 1 , respectively. Interventions targeted at medical students had a mean quality rating of 2.36, ranging from 1 to 3 . Among the seven studies assessing content, the effect sizes were not homogeneous and ranged from -0.17 to 1.56 . The outlier for this study was a negative effect size for the one instructional intervention [15]. Removing this outlier, interventions exhibited moderate to large effects on enhancing content of providers interviewing skills.

Ten of 11 studies examining technique (see Table 4 ) provided data with which to calculate effect size. Effect sizes were not homogeneous; they ranged from -0.27 to 2.36 . As with content skills, results varied within intervention types but generally indicated a moderate to large impact on interviewing technique.

Interventions targeted at residents had a mean quality rating of 1 and ranged from 0 to 4. Effect size could not be calculated for four studies examining content because the necessary data were not provided. For technique, only 1 of 7 studies provided sufficient data with which to calculate effect size [27].

The three studies targeted at communitybased physicians and child health associates $[21-22,46]$ were similar to resident interventions, in that no studies provided sufficient data with which to calculate effect size.

Behavioral retention studies. Among behavioral retention studies the mean quality 
rating was 2.8 and ranged from 2 to 4 . Unfortunately, only one study provided the necessary data to calculate effect size [44].

In summary, among interventions targeted at providers other than medical students, including the behavioral retention studies, the majority of articles failed to include the necessary data to calculate effect sizes. As a result, little can be concluded about the relative efficacy of these interventions on provider interviewing skills.

Patient-care outcomes. Patient-targeted interventions were more likely than providertargeted interventions to include patient-care outcomes in their studies. Given the diversity of outcomes examined across studies, effect sizes were not calculated for patient-care outcomes. However, major findings for these variables are reported in the appendices.

\section{Summary and discussion}

This study was designed to: (a) provide a review of intervention studies designed to enhance the communicative skills of healthcare providers and/or patients; (b) address similarities and differences in methodologies, strategies and outcomes of these investigations; (c) contrast and summarize interventions targeted at various communicative behaviors. A descriptive review of 40 studies revealed considerable variation in the types of interventions employed and the types of communicative behaviors studied. A breakdown of interventions and calculation of effect sizes offered the basis for comparison and preliminary discussions of the impact of interventions targeted at interpersonal processes and interviewing skills. The conclusions of this study, however, must be considered in light of the limitations posed by the studies themselves as well as the metaanalytic procedures employed.

\section{Limitations of the data}

Only some of the more critical methodological concerns are discussed here. These points generally pertain to a number of studies rather than to one or two isolated studies. The follow- ing discussion of critical methodological concerns includes: (a) defining the treatment; (b) sample size and subject descriptions; (c) assessment of dependent variables; (d) maintenance and generalization.

Defining the treatment. One of the most persistent problems encountered is inadequate description. Many studies provide incomplete descriptions of their interventions, with information about the duration, frequency and cost of interventions being most consistently omitted. This is a particular problem for interventions reported in the medical literature. Another limitation of these studies lies in the inadequate conceptualization of the intervention and its intended effects. With few notable exceptions $[12,14,23,24,32,35]$, most studies do not reveal any underlying theory guiding the selection of intervention strategies and communication behaviors. For the purposes of this paper, we employed social cognitive theory [10] to classify and group intervention types. Without clear conceptual linkages between intervention strategies and communicative behaviors it is not possible to identify the mechanisms related to behavioral change.

Sample size and description. Without information about sample size the reader is hard pressed to tell whether nonsignificant findings are due to low power to detect group differences or merely a weak intervention. Study weaknesscs are primarily due to small samplc sizes and/or failure to employ random assignment. When sample size is small, the power of a statistical test is reduced, thus increasing the probability of a type II error. For example, when the researcher aims for a two-tailed test of means with minimum power of 0.80 at the alpha level of 0.05 , a minimum of 64 subjects per group is required to detect a medium-sized effect $(d=0.50)$ [50]. Future studics should indicate safeguards taken against both Type I and II errors [50].

Much information is lost through sparse reporting of the demographic attributes of study samples. For example, among provider 
interventions it is rarely possible to abstract more than subjects' ycar in medical training. Likewise, the characteristics of interactants are often unreported. Given the established importance of demographic characteristics of the interactants in descriptive studies [1], more attention should be paid to reporting and analyzing the impact of these variables in intervention research. Finally, how subjects are selected into the study is frequently confined to a sentence or two and in some cases was altogether absent.

Dependent variables. Analysis of communication exchanges in research on patient-provider relationships is complicated but critical. Perusal of the appendices reveals a number of instances where investigators conducted a separate analysis for each item comprising a scale. Consequently, significant differences between groups are found for some items but not others. The practice of performing multiple tests should be avoided because it is likely to capitalize on chance. In future studies, when authors seek to reduce a large number of items into subcategories, we recommend that factor analytic methods, based on sound theory, be employed [69-70].

Interaction analysis systems used in the studies reviewed vary widely in terms of their origin and methodology. In terms of provider interventions, more attention should be paid to patient education techniques. For patient communication, future studies should be cxpected to extend assessments beyond question-asking behavior. Examples of variables to be measured include indices of patient information-seeking behavior [29-31], patient disclosures [24] and time disposition measures (e.g., latency of patients' initiation of topics) [23-24]. Future studies need to also attend to content of the interaction, which may help to establish linkages between communication behaviors and patientprovider role relationships [47]. Furthermore, research could benefit from studies that compare various interaction analysis systems [71].

Although there is general agreement that the goal of these interventions is to improve patient care, few of the studies on provider interventions actually examine patient-care outcomes. Although the majority of patient oriented studies examine some type of outcome beyond communicative behaviors, most focus on immediate outcomes such as patient satisfaction. The studies of Greenfield et al. [29-31] are unique in that they report on the impact of interventions on health status variables (see [31] for a summary of this work).

Maintenance and generalization. Most research is being conducted in naturalist medical care settings; however, a large number of the interventions focus on interviewing skills that are specific to a speciality (e.g., psychiatry) and/or do not take into account contextual factors (e.g., type of illness). Teaching preclinical students frequently involved interactions with simulated patients. Whether or not the skills acquired through these mechanisms generalize to other situations is yet to be shown. The longterm efficacy of interventions is largely unknown because so few behavioral-retention studies have been published.

Strengths and limitations of this meta-analysis

This study addressed a primary criticism of meta-analysis by following specified procedures intended to maximize reliability and validity [50]. Interrater reliability of coding was enhanced by independently reviewing all studies. Sampling bias, for example, was reduced by the exhaustive measures taken to search and retrieve studies using both computer and manual strategies. However, other unpublished reports of interventions may exist that are not included in this review. Conclusions drawn from reviews of published studies always run the risk of the so-called file-drawer bias.

The necessity of subgrouping outcomes by target groups produced smaller cell sizes than are desirable. This decision to favor distinct subgroupings of studies was made to avoid the apples and oranges problem discussed by Glass et al. [8] and to provide a more detailed analysis 
Table 5. Checklist for patient/provider communication interventions.

1. Has a needs assessment been conducted (i.e., have the perceptions and needs of patients and providers been determined)?

2. What communicative behaviors are going to be the target of intervention?

3. Is there clear theoretical rationale for the strategies chosen to effect the desired outcomes (both communicative behaviors and patient-care outcomes)?

4. Is there an explicit scheme for planned intervention?

5. Are the resources required to conduct the intervention available?

6. Is there support from the staff that will be involved in the program?

7. Is there a plan for evaluation?

8. In preparing reports and publications, are the sample characteristics, methods, and statistical analyses described thoroughly?

of the effects of interventions on differing types of outcome. The heterogeneity of most of the subgroups attests to the appropriateness of our decision.

\section{Practical implications}

Based on our literature review, we now pose some key questions for patient educators to consider when developing communication interventions. Through examining the questions listed in Table 5 we hope to identify some of the ways in which patient educators can contribute to the development of communication interventions.

The importance of assessing antecedent factors to patient-provider interactions is listed first in Table 5. This is a direct result of the increasing recognition that the success of patientprovider communication is due, in part, to preexisting beliefs brought to the interaction by all participants. Simonds [72], for example, recommends that a behavioral-educational diagnosis can be applied to guide assessment processes. In addition, specific instruments have been developed to assess patients' desires for control in the medical interactions [73]. Patient educators might also benefit from drawing upon the work of other disciplines, such as Kleinman's anthropological conceptualization of explanatory models of illness and the negotiated meaning within the encounter [74]. Patient educators can provide input regarding which patients may benefit from a specific type of intervention and under what conditions.

Questions 2 and 3 pertain directly to developing communication interventions. These issues were discussed in considerable detail in the prior section on dependent variables, therefore, only a few key points will be reiterated here. As noted by Strecher [75], the repertoire of interpersonal skills addressed in much of the medical education literature is based on counseling models and tends to be weighted heavily toward information-gathering skills. Relatively little attention is devoted to information provision, patients' understanding of information given, or education about preventive practices or self-management skills.

Physicians need to develop a repertoire of patient-education strategies for use in their time limited interactions with patients [76]. For example, clinicians who lack training in setting achievable behavioral objectives and goals are likely to focus their educational efforts on outcome (e.g., lose 50 pounds) rather than behaviors and, therefore, leave the patient to his/her own devices. To date, health care providers have not been rewarded for time spent informing and educating patients [77]. The approaches adopted towards communication interventions will obviously be influenced by 
professional norms and values. A structural change at the macro level of the health care system, in addition to micro level changes, may be necessary to advance educational interventions.

Surprisingly, most interventions have only examined dyadic relationships between a single patient and provider. As shown quite recently, the presence of a companion is not uncommon in medical consultations [78]. Health care providers' skills in interacting with patients and their companions have received little attention. Strategies designed to marshal support from companions are discussed in the practiceoriented literature [79] but await testing in terms of communication interventions.

As indicated previously, a primary limitation of these studies is the lack of theoretical models to guide investigators. However, this situation appears to be changing of late. For example, Roter et al. [1] have introduced an explanatory model of medical encounters, entitled the "theory of reciprocity." Additionally, models of patient-provider interactions are described by Pendleton et al. [80], Tuckett et al. [81], Kleinman [74] and Demak and Becker [77], to name a few. It is yet to be seen how these models influence the development of communication interventions.

The fourth question posed asks if there is an explicit scheme for planned intervention. In the intervention studies to date, little attention has been given to targeting the communicative behaviors of both providers and patients simultaneously. These two arenas need to be integrated more fully in order to maximize the potential impact of interventions. Patientprovider relations should benefit when both patient and provider give and receive adequate information. Although the majority of interventions targeted at either patients or providers have shown promise for short-term effects on communicative behaviors, unless communication is observed and measured over longer periods of time, conclusions about the longterm effects of these interventions on patient- provider interactions are limited. Long-term maintenance of behaviors may require multiple opportunities for skill practice and reinforcement.

Having stated the ways that patient educators can contribute to the development of interventions, the next set of questions ( 5 and 6 ) focuses on the issue of resources, both monetary as well as support from staff. Although cost analyses were not available in this review, interventions clearly vary in their scope and required time of clinical staff. Indeed, a number of the interventions described in this review do not conform to the traditional clinic atmosphere. Some interventions, such as videotaped modeling, may offer several programmatic advantages over face-to-face didactic interventions. For example, modeling interventions may be incorporated directly into patient education videotapes, allowing clinical staff more time to work on elements such as skill practice and feedback. We need interventions that allow for convenient transfer to similar patient populations and clinical settings.

The final set of questions focuses on the design and reporting of communication interventions. Practitioners and researchers must combat a number of fundamental problems for progress to continue. The need for theory to guide the development of interventions, current methodological limitations and the changing complexion of the medical care encounters are among these important considerations [82]. In addition, practitioners have the responsibility of making their research methods and findings accessible to clinical and research audiences. In this regard, intervention programs could benefit from collaborative work with interdisciplinary teams, including health educators, psychologists, clinicians and medical educators.

The next few years will be exciting and challenging. We are facing the challenge of collaborating with other disciplines to construct efficient and effective ways of integrating communication intervention into ongoing medical care. The findings from our review support the 
view that communication interventions are a sound approach for enhancing patient and provider communicative skills. The difficulties that we confront are not insignificant but the prize may be improved care for patients and more rewarding interactions for both patients and providers.

\section{Acknowledgments}

We would like to thank Lisa L. Konkol and J. Kenneth Conover for their helpful comments on earlier drafts of this paper. PAS acknowledges National Institute on Aging Research Training Grant No. T32-AG00134.

\section{References}

1 Roter DL, Hall JA, Katz NR: Patient-physician communication: a descriptive summary of the literature. Patient Educ Couns 1988; 12: 99-119.

2 Hall JA, Roter DL, Katz. NR: Meta-analysis of correlates of provider behavior in medical encounters. Med Care 1988; 26: $657-675$.

3 Kraemer HC, Andrews G: A nonparametric technique for meta-analysis effect size calculation. Psychol Bull 1982; 91: $404-412$.

4 Oetting ER: Program evaluation, scientific inquiry and counseling psychology. Couns Psychol 1982; 10: 61-70.

5 Kauss DR, Robbins AS, Abrass I et al: The long-term effectiveness of interpersonal skills training in medical schools. J Med Educ 1980; 55: 595-601.

6 Kramer D, Ber R, Moore M: Impact of workshop on students' and physicians' rejecting behaviors in patient interviews. J Med Educ 1987; 62: 904 -910.

7 Cohen J: A coefficient of agreement for nominal scales. Educ Psychol Meas 1960; 20: 37-46.

8 Glass G: Integrating findings: the meta-analysis of research. Rev Res Educ 1977; 5: 351-379.

9 Padgett D, Mumford E, Hynes M, Carter R: Meta-analysis of the effects of educational and psychological interventions on management of diabetes mellitus. J Clin Epidemiol 1988; 41: $1007-1030$.

10 Bandura $\Lambda$ : Social Foundations of Thought and Action: A Social Cognitive Theory. Englewood Cliffs, NJ: Prentice Hall, 1986.

11 Rosenthal TL, Bandura A: Psychological modeling: theory and practice. In: Garfield SL, Bergin AE eds. Handbook of Psychotherapy and Behavior Change: An Empirical Analysis, 2nd edn. New York: Wiley, 1978, pp. 621-658.

12 Roter DL: Patient participation in the patient-provider interaction: the effects of patient question asking on the quality of interaction, satisfaction and compliance. Health Educ Monogr 1977; 5: 281-311.

13 Robinson EJ, Whitfield MJ: Improving the efficiency of pa- tients' comprehension monitoring: a way of increasing patients' participation in general practice consultations. Soc Sci Med 1985; 21: 915-919.

14 Tabak ER: Encouraging patient question-asking: a clinical trial. Patient Educ Couns 1988; 12: 37-49.

15 Wolraich ML, Albanese M, Reiter-Thayer S, Barratt W: The effects of medical information and extent of training on the interviewing skills of medical students. Proc Annu Conf Res Med Educ 1981; 20: 9-15.

16 Stillman PL, Sabers DL, Redfield DL: Use of trained mothers to teach interviewing skills to first-year medical students: a follow-up study. Pediatrics 1977; 60: 165-169.

17 Stillman PL, Sabers DL, Redfield DL: The use of paraprofessionals to teach interviewing skills. Pediatrics 1976; 57: 769-774.

18 Scheidt PC, Lazorita S, Ebbeling WL et al: Evaluation of system providing feedback to students on videotaped patient encounters. J Med Educ 1986; 61: 585-590.

19 Farsad P, Galliguez P, Charberlin R, Roghmann KJ Teaching interviewing skills to pediatric house officers. Pediatrics 1978; 61: 384-388.

20 Dickenson ML, Huels M, Murphy MD: Pediatric house staff communication skills: assessment and intervention. $J$ Med Educ 1983; 58: 659-662.

21 Verby JE, Holden P, Davis RH: Peer review of consultations in primary care: the use of audiovisual recordings. $\mathrm{Br}$ Med J 1979; 1: 1686-1688.

22 Terry PB, Wang VL, Flynn BS et al: A continuing medical education program in chronic obstructive pulmonary diseases: design and outcome. Am Rev Respir Dis 1981; 123: $42-46$.

23 Wallston BS, Wallston KA, DeVellis BM, Percy J: Modification of question asking behavior in high and low assertive women through modeling and instructions. Soc Behav Pers 1979; 6: 195-204.

24 Anderson LA, DeVellis BM, DeVellis RF: Effects of modeling on patient communication, knowledge and satisfaction. Med Care 1987; 25: 1044-1056.

25 Alroy G, Ber R, Kramer D: An evaluation of the shortterm effects of an interpersonal skills course. Med Educ 1984; 18: 85-89.

26 Naji SA, Maguire GP, Fairbairn SA et al: Training clinical teachers in psychiatry to teach interviewing skills to medical students. Med Educ 1986; 20: 140-147.

27 Mason JL, Barkley SE, Kappelman MM et al: Evaluation of a self-instructional method for improving doctor-patient communication. J Med Educ 1988; 63: 629-635.

28 Sullivan JA, Grover PL, Lynaugh JE et al: Video mediated self-cognition and the Amidon-Flanders interaction analysis model in the training of nurse practitioners' history taking skills. J Nurs Educ 1975; 14: $39-45$.

29 Greenfield S, Kaplan SH, Ware JE: Expanding patient involvement in care. Ann Intern Med 1985; 102: 520- 528.

30 Greenfield S, Kaplan SH, Ware JE et al: Patients' participation in medical care: effects on blood sugar control and quality of life in diabetes. J Gen Intern Med 1988; 3: $448-457$. 
31 Kaplan SH, Greenfield S, Ware JE: Assessing the effects of physician-patient interactions on the outcomes of chronic disease. Med Care 1989; 27: S110-S127.

32 Moreland JR, Ivey AE, Phillips JS: An evaluation of microcounseling as an interviewer training tool. J Consult Clin Psychol 1973; 41: 294-300.

33 Maguire GP, Clarke D, Jolley B: An experimental comparison of three courses in history-taking skills for medical students. Med Educ 1977; 11: 175-182.

34 Betchart NS, Anderson DG, Thompson TL, Mumford E: A tutorial approach to improving medical students' interviewing skills. J Med Educ 1984; 59: $431-433$.

35 Weihs K, Chapados JT: Interviewing skills training - A study. Soc Sci Med 1986; 23: 31-34.

36 Maguire P, Roe P, Goldberg D et al: The value of feedback in teaching interviewing skills to medical students. Psychol Med 1978; 8: 695-704.

37 Quirk M, Babineau RA: Teaching interviewing skills to students in clinical years: a comparative analysis of three strategies. J Med Educ 1982; 57: 939-941.

38 Faber RJ, Out J, Reepmaker J: Teaching interviewing skills to pediatric junior clerks using simulated mothers. Med Educ 1984; 18: 255-261.

39 Adler LM, Ware JE, Enelow AJ: Changes in medical interviewing style after instruction with two closed-circuit television techniques. J Med Educ 1970; 45: 21-28.

40 Levin EM, Scurry MT, Bosshart DA: The teaching of interviewing and counseling skills to internal medicine residents. J Med Educ 1979; 54: 819-821.

41 Robbins AS, Kauss DR, Heinrich R et al: Interpersonal skills training: evaluation in an internal medicine residency. J Med Educ 1979; 54: 885-894.

42 Verby J, Davis RH, Holden P: A study of the interviewing skills of trainee assistants in general practice. Patient Couns Health Educ 1980; 2: 68-71.

43 Putnam SM, Stiles WB, Jacob MC, James SA: Teaching the medical interview: an intervention study. J Gen Intern Med 1988; 3: 38-47.

44 Maguire P, Fairbairn S, Fletcher C: Consultation skills of young doctors: $\mathrm{I}$ - Benefits of feedback training in interviewing as students persist. Br Med J 1986; 292: 1573-1576.

45 Maguire P, Fairbairn S, Fletcher C: 11 - Most young doctors are bad at giving information. Br Med J 1986; 292: $1576-1578$.

46 Hutter MJ, Dungy CI, Zakus GE et al: Interviewing skills: a comprehensive approach to teaching and evaluation. $\mathbf{J}$ Med Educ 1977; 52: 328-333.

47 Hinckley JJ, Craig H, Anderson LA: The communication characteristics of provider-patient information exchanges. In: Giles $\mathbf{H}$, Peterson $\mathbf{P}$ eds. Handbook of Language and Social Psychology. New York: Wiley, 1990, pp. 519-539.

48 Lipkin M: The medical interview and related skills. In: Branch WT ed. The Office Practice of Medicine. Philadelphia, PA: WB Saunders, 1987, pp. 1287-1306.

49 Carroll JG, Monroe J: Teaching clinical interviewing in the health professions. Eval Health Prof $1980 ; 3: 21-45$.

50 Cohen J: Statistical power analysis for the behavioral sciences. Hillsdale: Lawrence Erlbaum Associates, 1988, pp. $19-66$.
51 Wolf FM: Meta-Analysis: Quantitative Methods for Research Synthesis. Beverly Hills: CA: Sage.

52 Percy JH: The effects of modeling on verbal disclosure of confusion. George Peabody College for Teachers, unpublished manuscript, 1975.

53 Adler LM, Enelow AJ: An instrument to measure skill in diagnostic interviewing: a teaching and evaluation tool. J Med Educ 1966: 41: 281-288.

54 Stiles WB: Verbal response modes and dimensions of interpersonal roles: a method of discourse analysis. J Pers Soc Psychol 1978; 36: 696-703.

55 Bales RF: Interaction Process Analysis. Cambridge, MA: Addison-Wesley, 1950.

56 Wolraich M, Albanese M, Reiter-Thayer S, Barratt W: Teaching pediatric residents to provide emotion-ladened information. J Med Educ 1981; 56: 438 - 440.

57 Campbell JR, Barnes CW: Interaction analysis - a breakthrough? Phi Delta Kappa 1969; 3: 587-590.

58 Ivey AE, Normington CJ, Miller $\mathrm{CD}$ et al: Microcounseling and attending behavior: an approach to prepracticum counselor training. Couns Psychol 1968; 5: 1-12.

59 Carkhuff RR: Interpersonal Skills and Human Productivity. Amherst, MA: Human Resources Development Press, 1983, pp. $76-86$.

60 Bijou SW, Peterson RF, Ault MH: A method to integrate descriptive and experimental field studies at the level of data and empirical concepts. J Appl Behav Anal 1968; 1: $175-191$.

61 Mumford E, Anderson D, Cuerdon T, Scully J: Performance-based evaluation of medical students' interviewing skills. J Med Educ 1984; 59: 133-135.

62 Brockway BS: Evaluating physician competency: what difference does it make? Eval Program Plann 1978; 1: $211-220$

63 Helfer R, Hess J: An experimental model for making objective measurements of interviewing skills. J Clin Psychol 1970; 26: 327-331.

64 Matarazzo R, Phillips J, Wiens A et al: Learning the art of interviewing: a study of what beginning students and their patterns of change. Psychother Theory Res Pract 1965: 2: 49-60.

65 Robbins AS: Teaching interpersonal skills in a medical residency training program. J Med Educ 1978; 53: 988-990.

66 Ley P: Patients' understanding and recall in clinical communication failure. In: Pendleton D, Hassler J eds. DoctorPatient Communication. London: Academic Press, 1983, pp. 89-108.

67 Kulik J: Book review. Review of G.V. Glass et al. metaanalysis in social research (Sage 1981). Eval News 1983; 4: $101-105$.

68 Rosenthal R: Meta-Analytic Procedures for Social Research. Beverly Hills, CA: Sage, 1984.

69 Kim J, Mueller C: Introduction to Factor Analysis. Beverly Hills: Sage, 1978.

70 Kim J, Mueller C: Factor Analysis: Statistical Methods and Practical lssues. Beverly Hills: Sage, 1978.

71 Inui TS, Carter WB, Kukuli WA, Haigh VH: Outcomebased doctor-patient in interaction analysis. Identifying ef- 
fective provider and patient behavior. Med Care 1982; 20 $535-549$.

72 Simonds SK: Individual health counselling and education: emerging directions from current theory, research and practice. Patient Couns Health Educ 1983; 4: 175-181.

73 Anderson LA, DeVellis RF, Boyles B, Feussner JR: Patients' perceptions of their clinical interactions: Development of the multidimensional desire for control scales. Health Educ Res 1989; 4: 383-397.

74 Kleinman A, Eisenberg L, Good B: Culture, illness and care. Clinical lessons from anthropologic and cross-cultural research. Ann Inter Med 1978; 88: 251-258.

75 Strecher VJ: Improving physician-patient interactions: a review. Patient Educ Couns 1983; 4: 129-132.

76 McClellan W: The physician and patient education: a review. Patient Educ Couns 1986; 8: 151--163.

77 Demak MM, Becker MH: The doctor patient relationship and counseling for preventive care. Patient Educ Couns 1987; 9: 5-24.

78 Beisecker AL, Fuemmeler EL: The companion's role in the doctor-elderly patient-companion interaction. Paper

\section{Appendices}

Column 1 lists the name of the author(s), year of publication, reference and study design. Column 2 describes the characteristics of the study sample, assessment period, trainers and interactants (i.e., patients or providers). In column 3, a brief synopsis of the treatment, control and/or comparison conditions are presented. Column 4 lists the major communicative variables studied as well as outcomes related to patient care. The final column specifies the major study findings. Note that Column 4 contains each dependent variable and Column 5 the corresponding findings. Other information pertaining to each appendix is provided in the corresponding endnotes. presented at the Gerontological Society of America Annual Meeting, Chicago, IL., 1986

79 Becker MH, Maiman LA: Strategies for enhancing patient compliance. J Commun Health 1983; 6: 113-135.

80 Pendleton D: Doctor-patient communication: a revicw. In: Pendleton D, Hasler J eds. Doctor-Patient Communication. London: Academic Press, 1983.

81 Tuckett D, Boulton M, Olson C, Williams A: Meetings Between Experts: An Approach to Sharing Ideas in Medical Consultations. London: Tavistock Publications, 1985.

82 Roter DL, Hall JA: Studies of doctor-patient interaction. Annu Rev Publ Health 1989; 10: 163-180.

Correspondence to:

Lynda A. Anderson

1420 Washington Heights

M5047 SPHII

University of Michigan

Ann Arbor

MI 48109-2029, USA
Statistical significance was defined as $P<$ 0.05 . The greater than symbol $(>)$ is used to indicate statistically significant differences in the dependent variable among the various treatment conditions being compared. The notation NS indicates that no significant differences were found between the groups on the variable of interest. We included findings based on total scale scores and subscale scores unless selective communicative variables that represented individual speech acts (i.e., question-asking behavior) or patterns (i.e., physician exposition) were assessed by the authors as the major variables of interest. Findings based on individual items that comprised a scale were not reported, even though some authors conducted these analyses in their studies. 


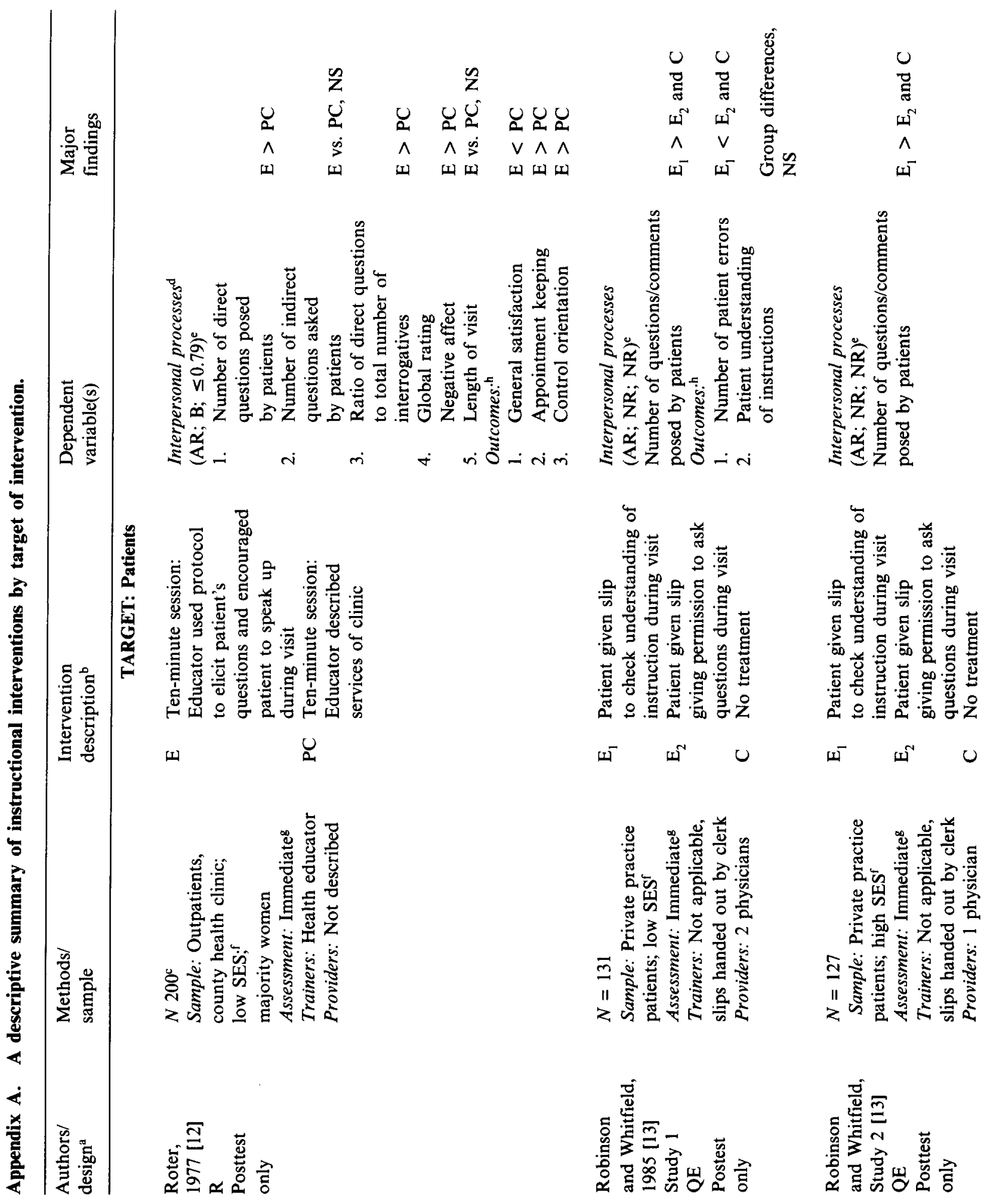



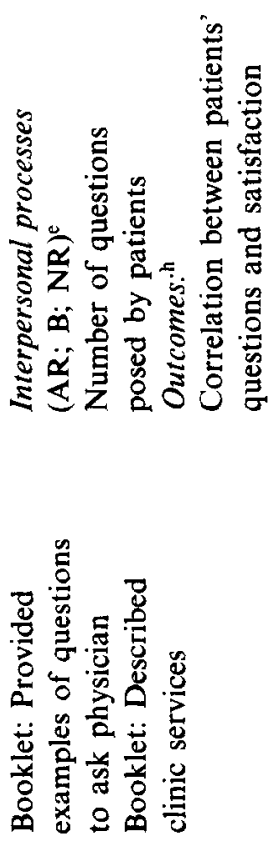

(1)

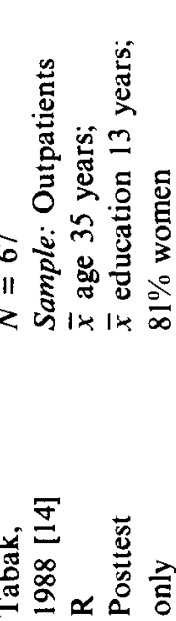

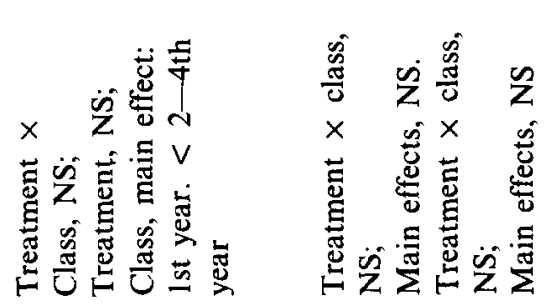

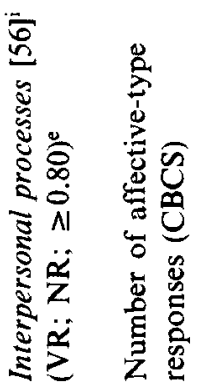
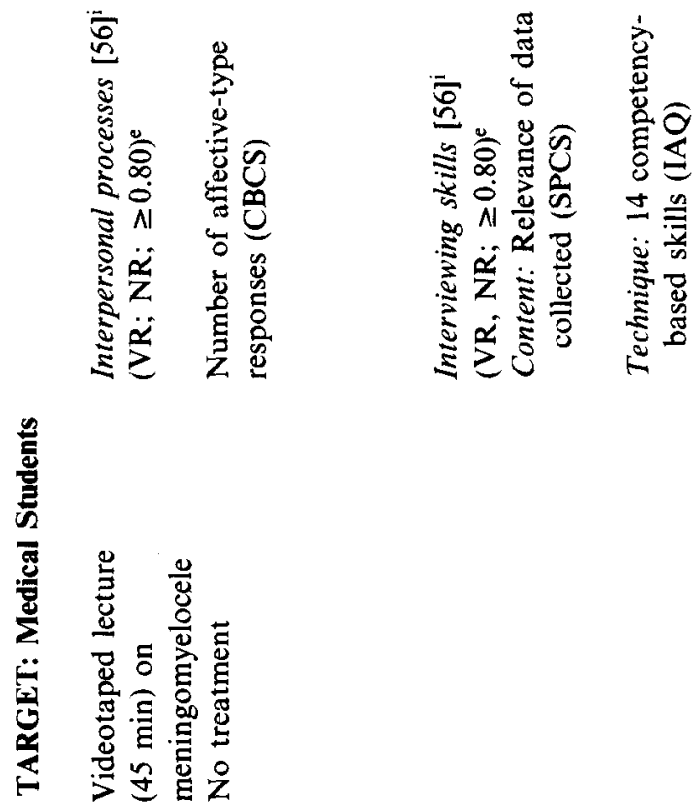

띠
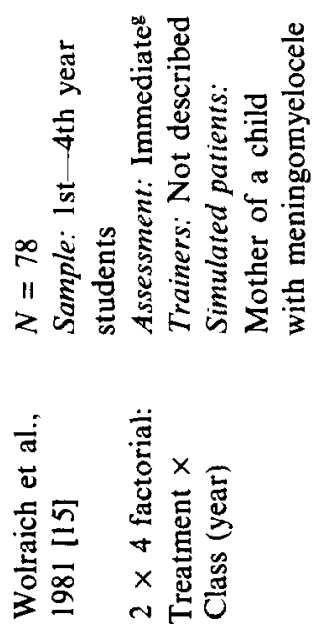

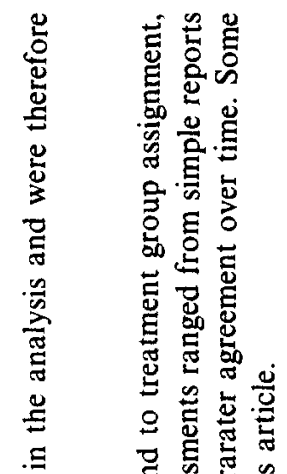

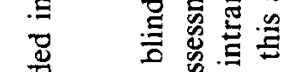

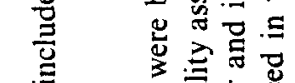

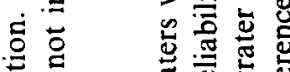

可产这

$3 \quad \quad \dot{0} \Xi$

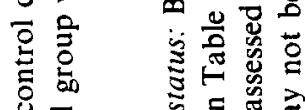

论

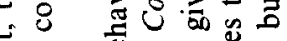

氙号

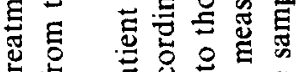
范导 总

. 巳

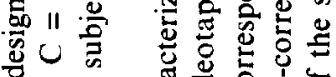

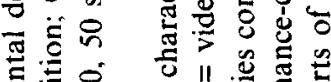
苞官 氙

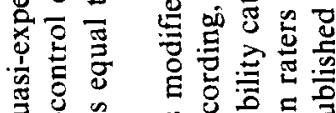

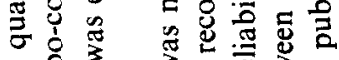

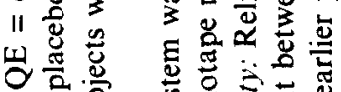

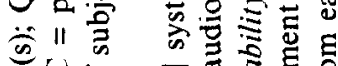

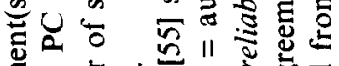

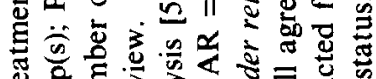

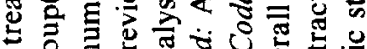

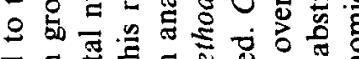

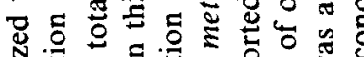

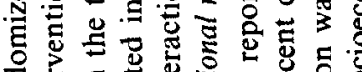
는

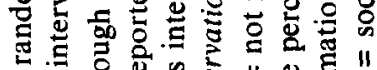
"1 

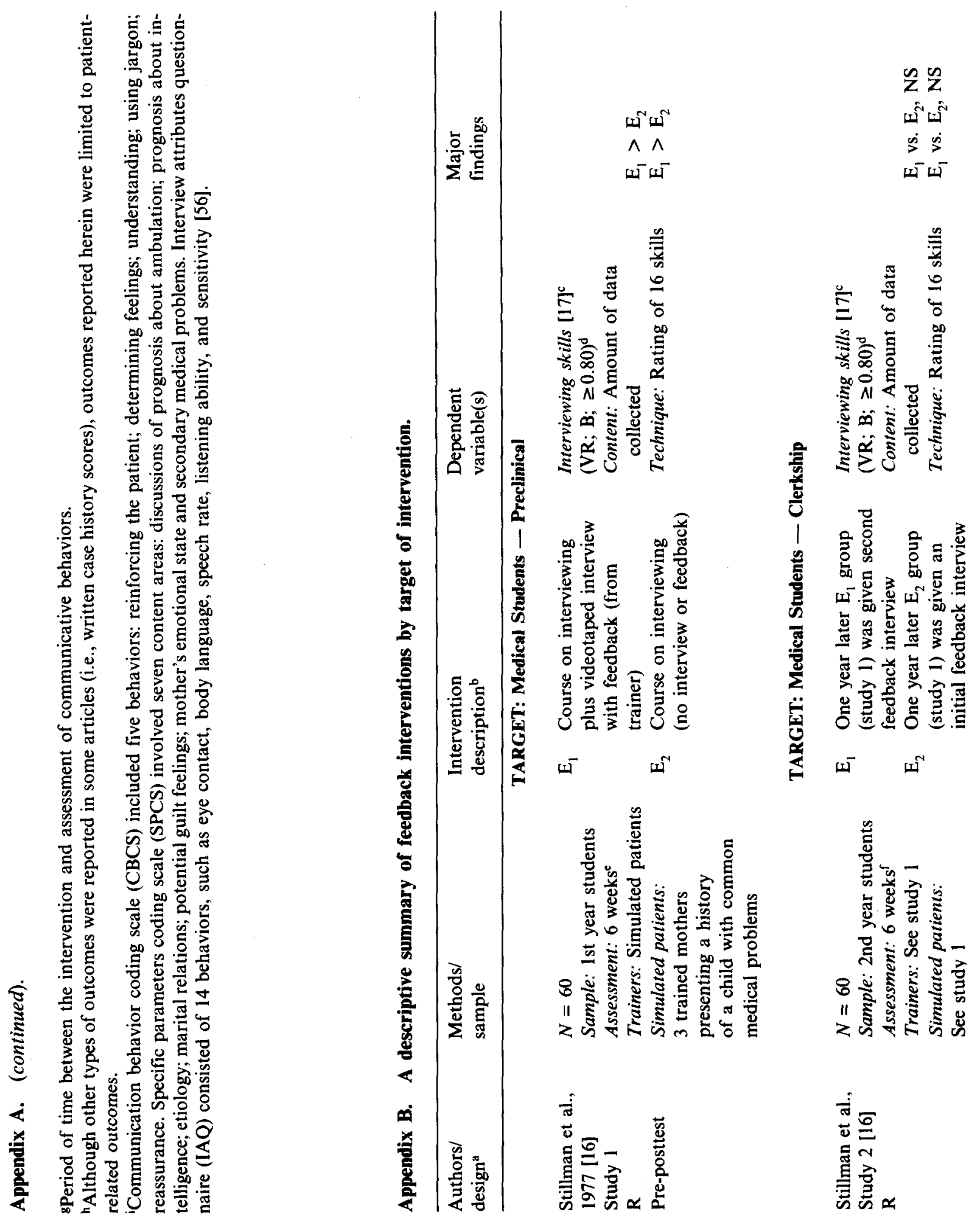


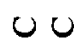

$\wedge \wedge$

山ᄄ

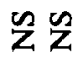

जैंज

$\dot{s}>$

ज्ञात्र
总

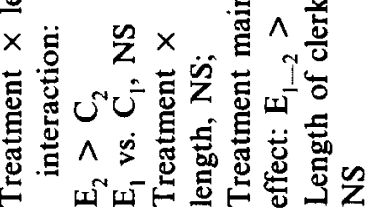

U

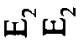

$\wedge \wedge$

प्ञ

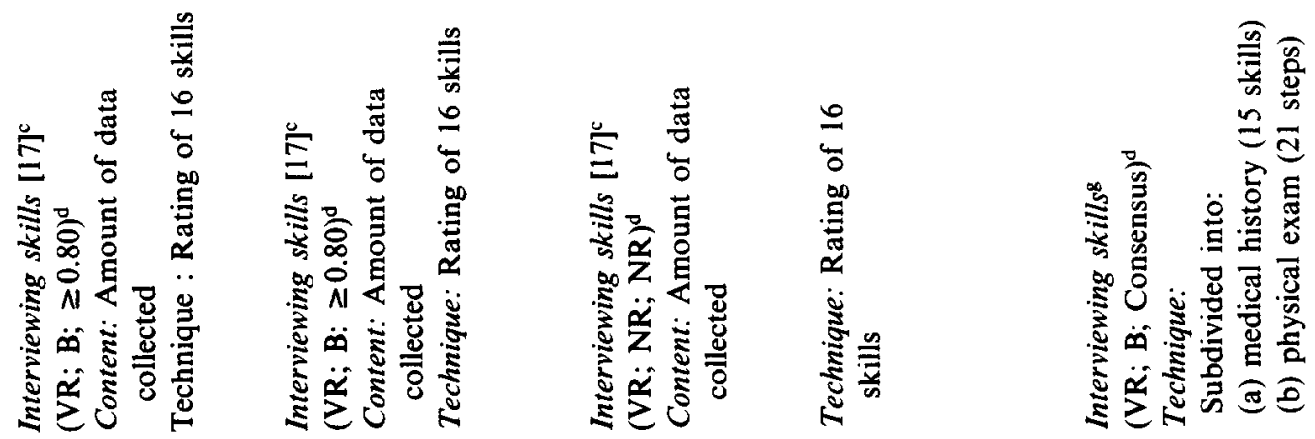

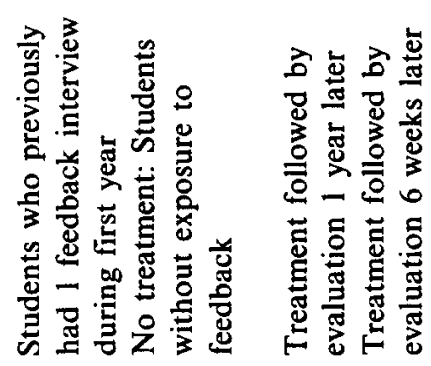

노
जิ जิ

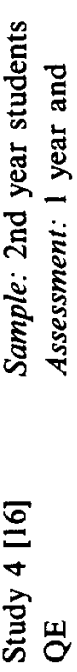

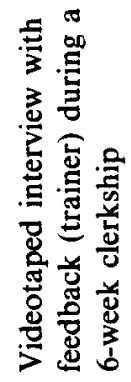

जิ

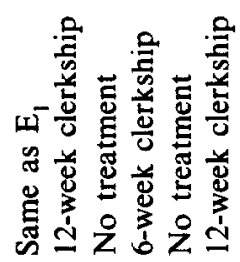

ज U

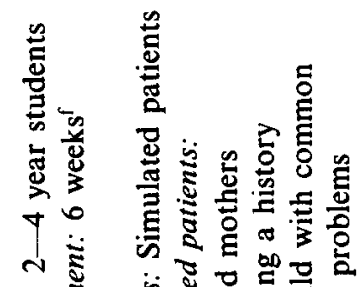

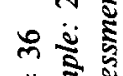
र ह

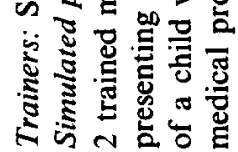

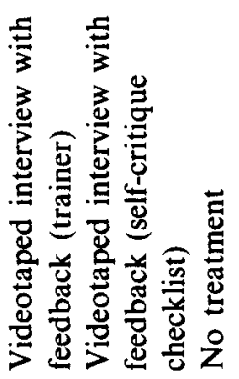

ज्ञ जी

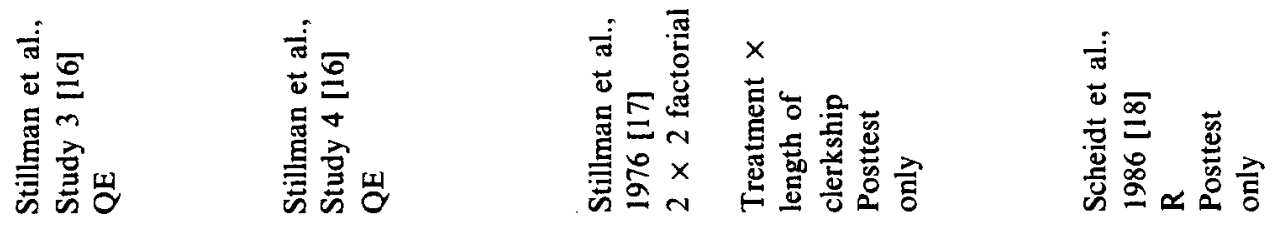




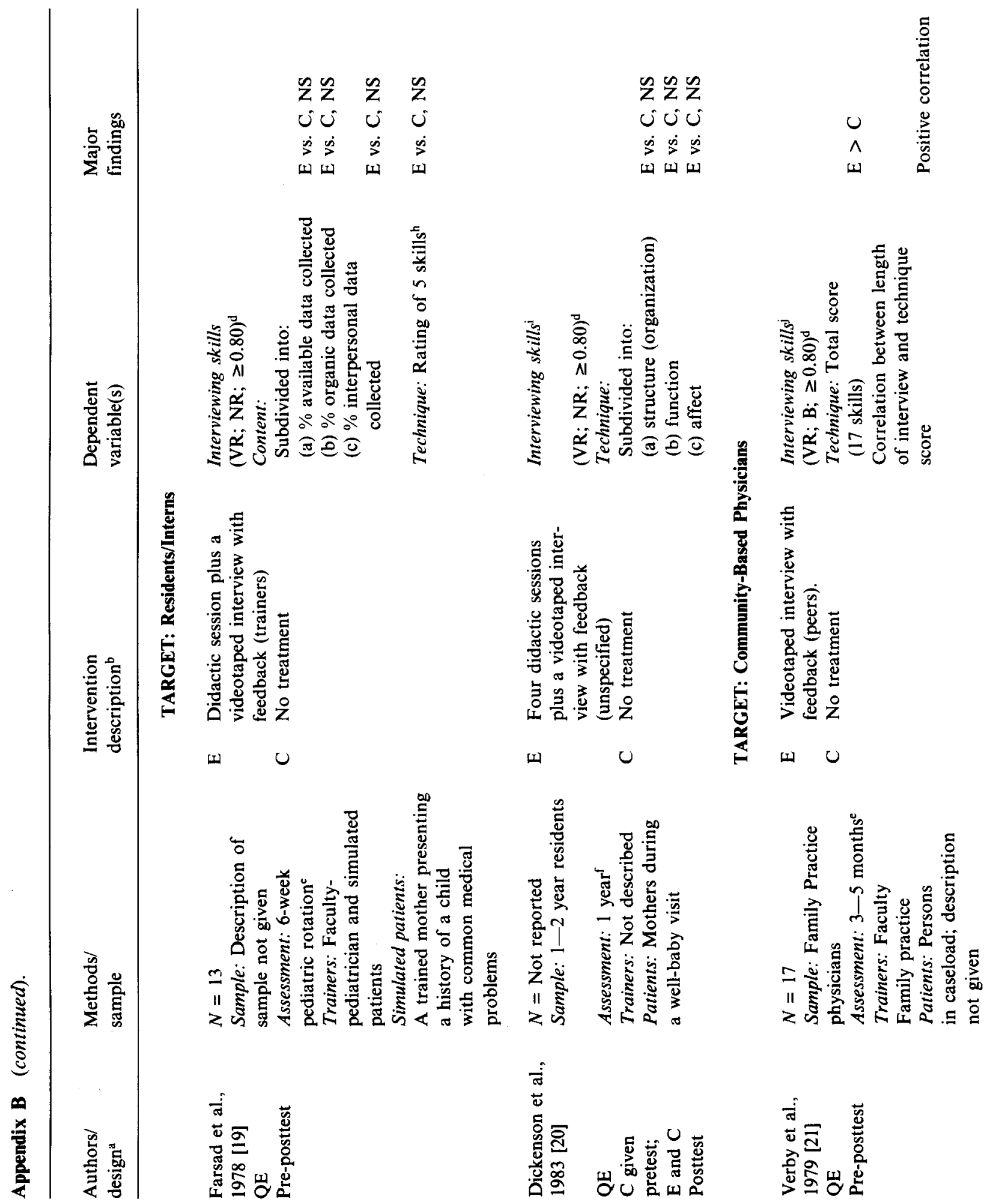




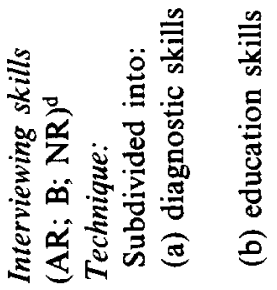

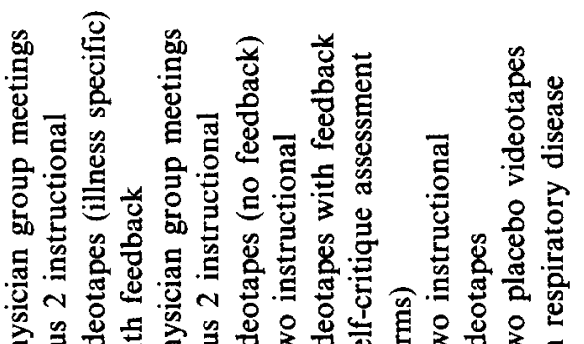

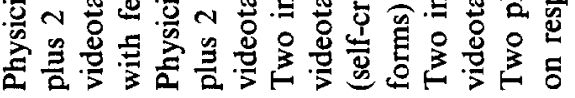

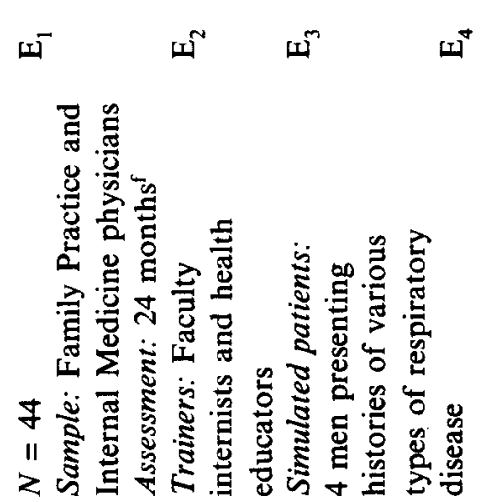

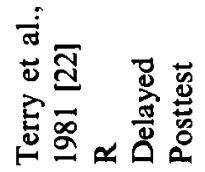

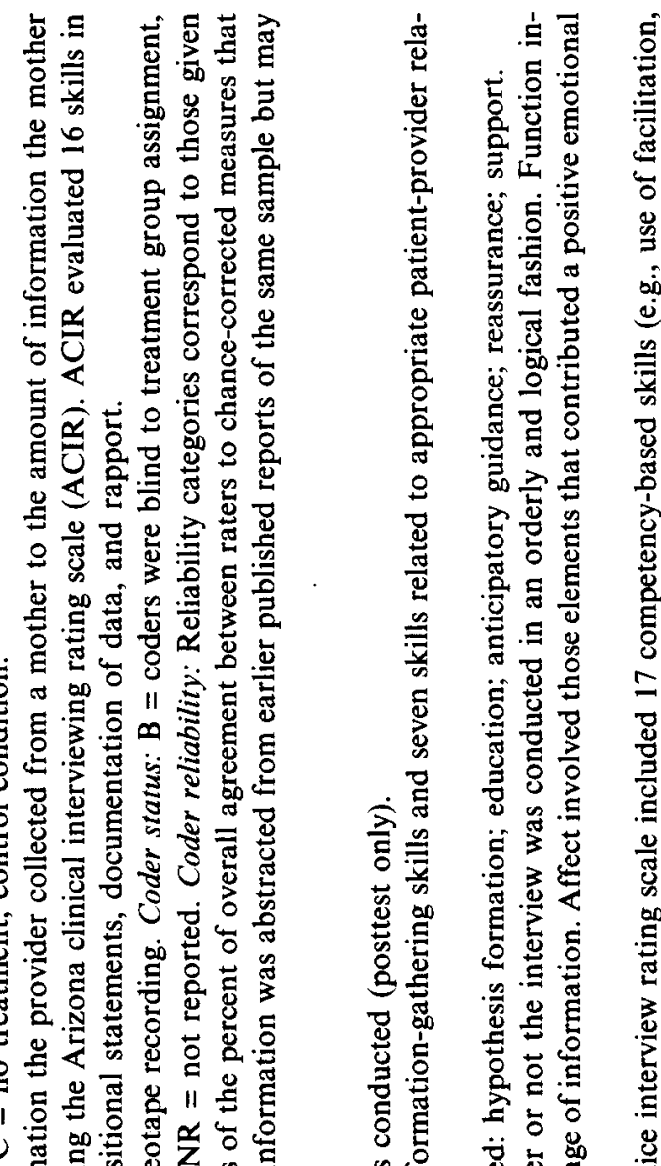

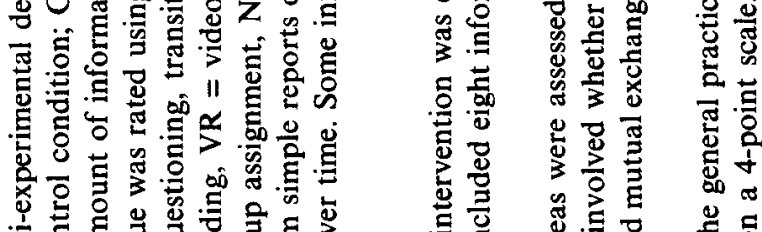

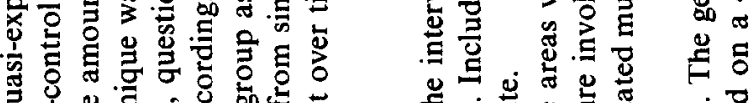

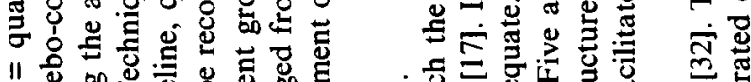

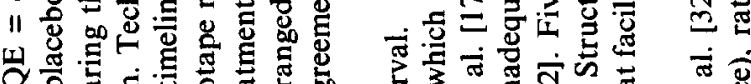

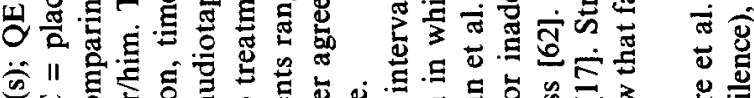

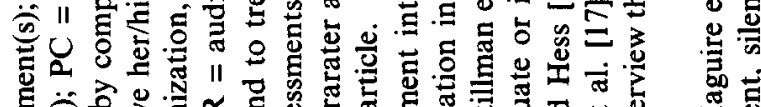

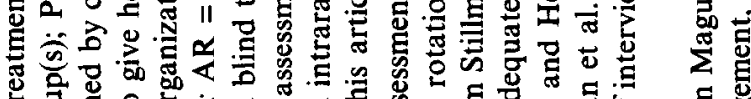

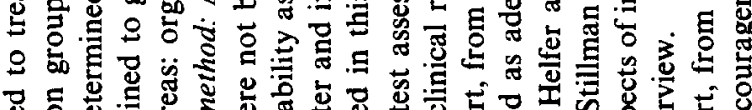

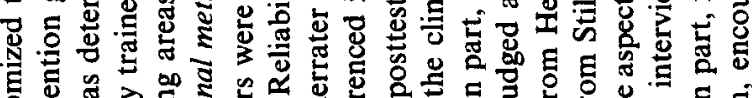

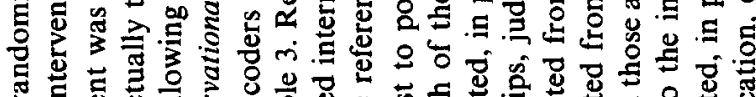

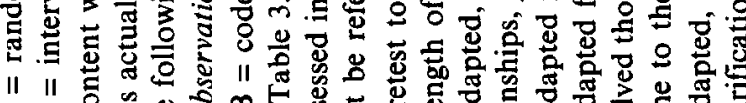
II II 


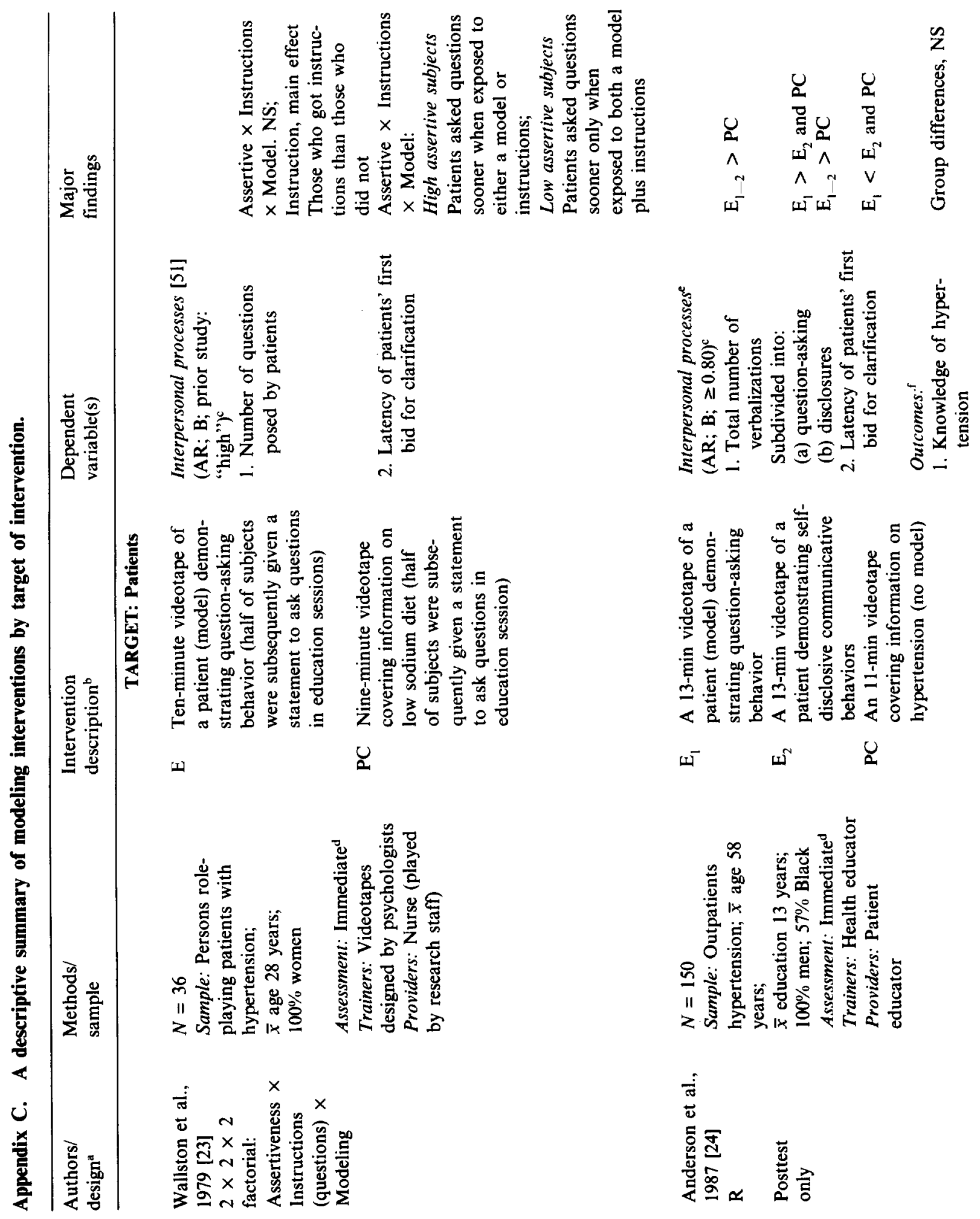


竞
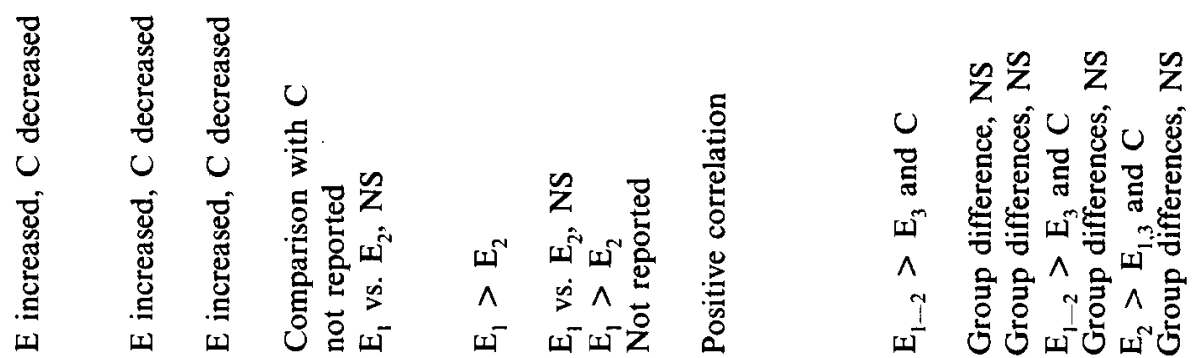

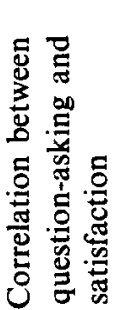

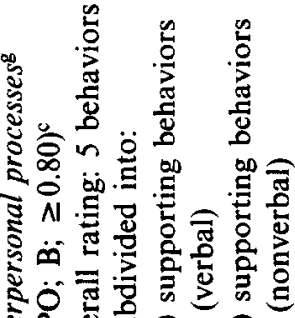

鲜

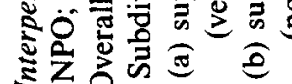

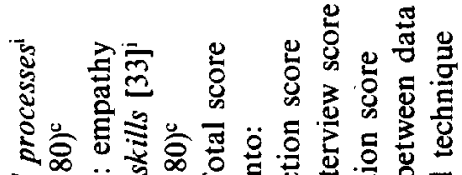

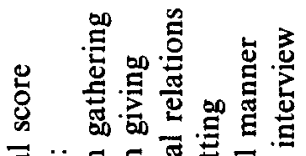

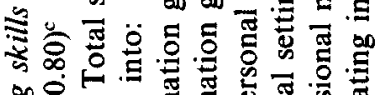

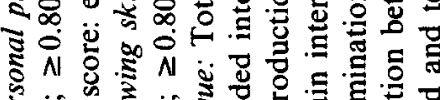

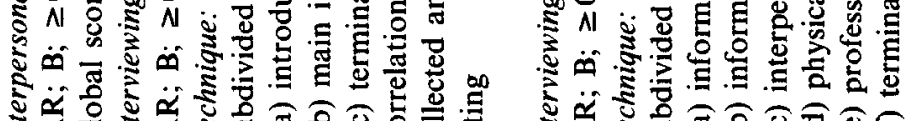
i
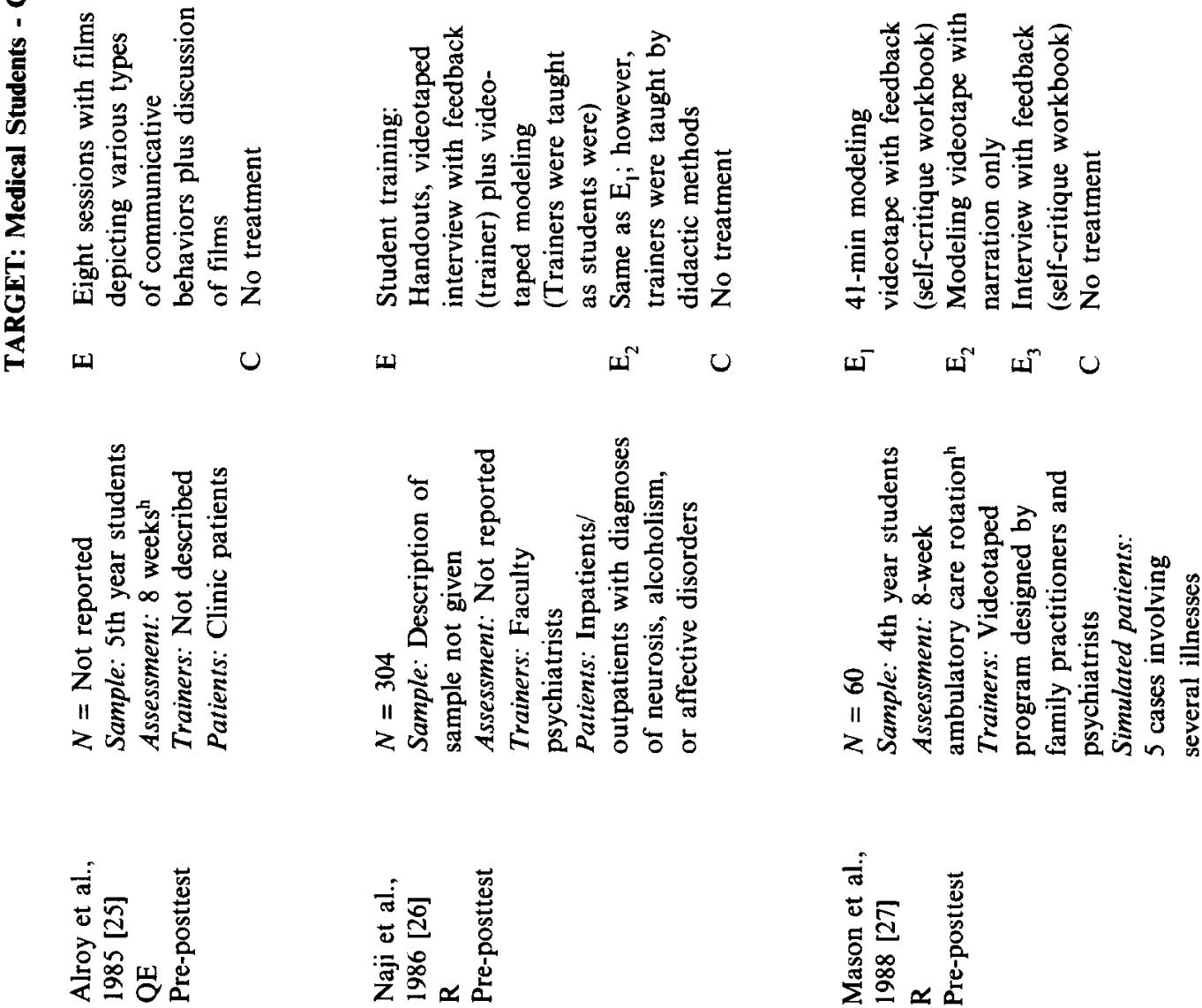


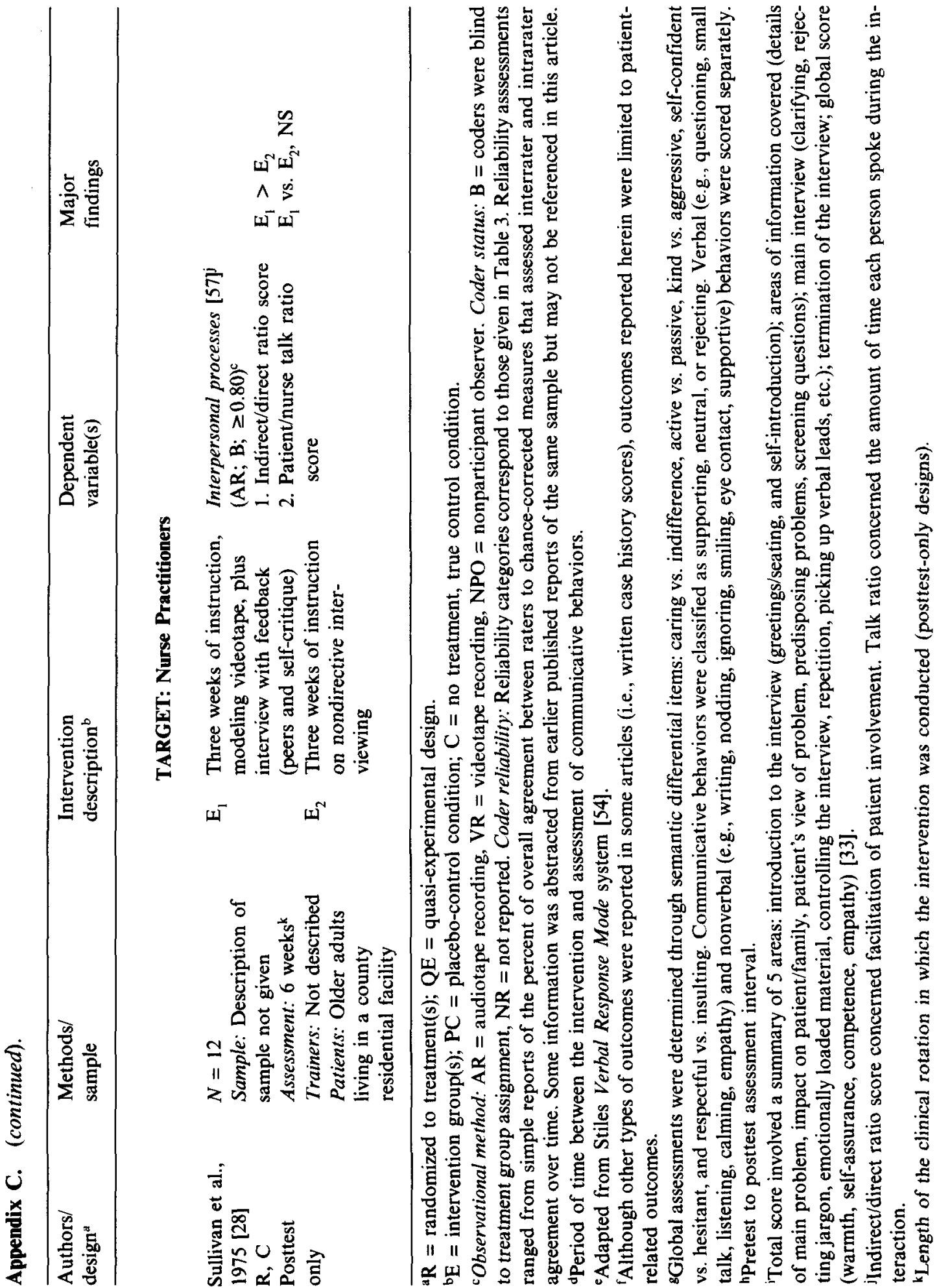




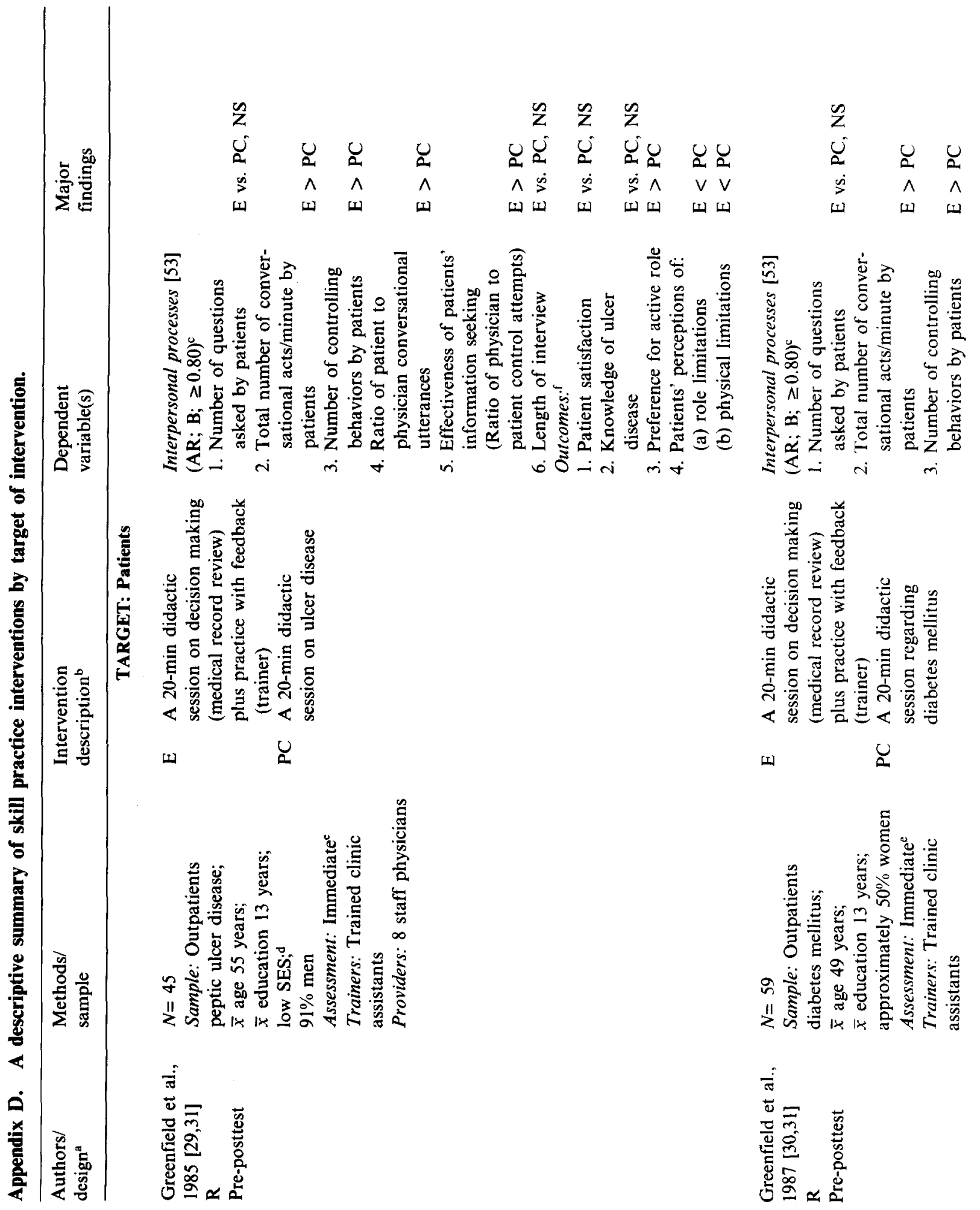




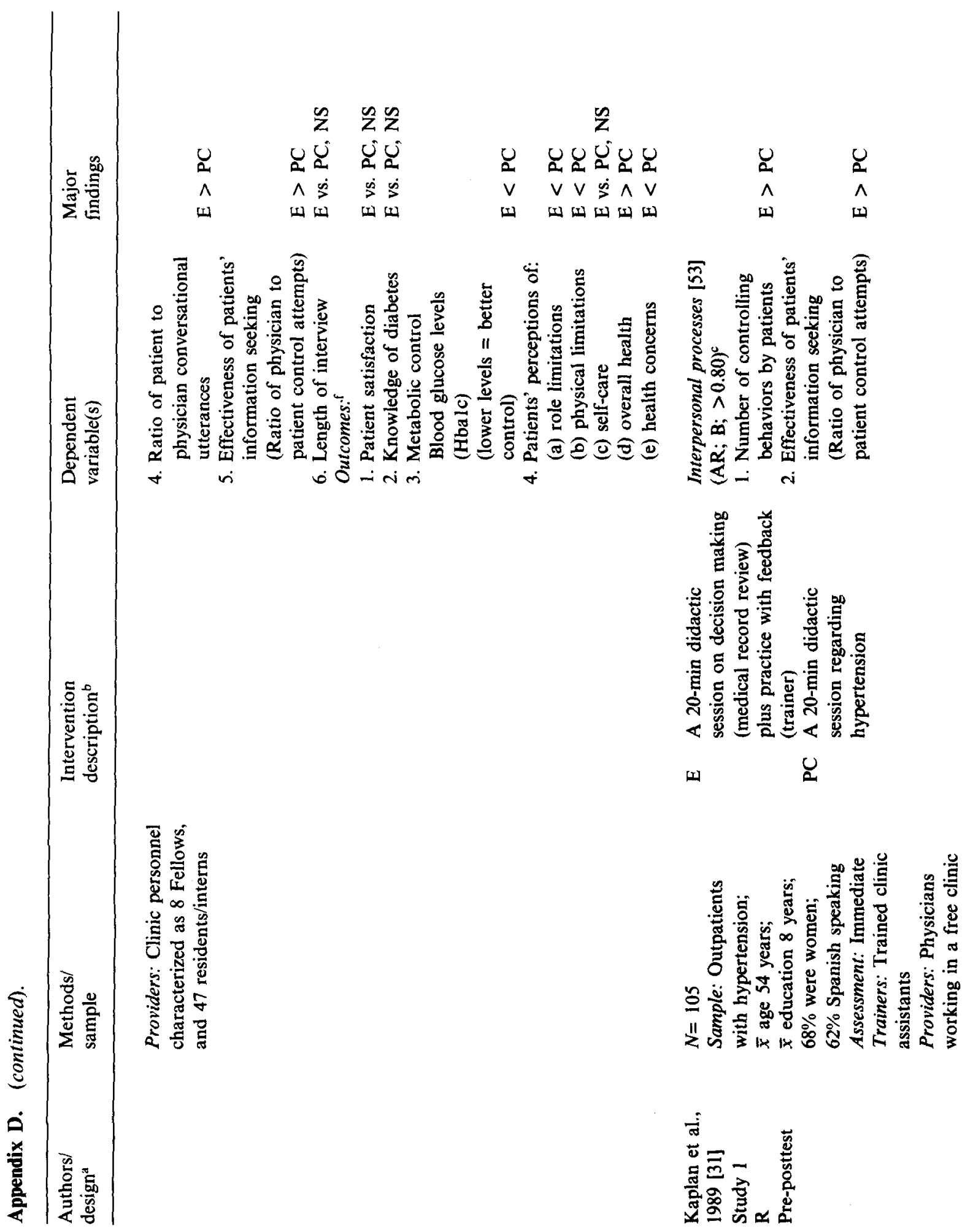




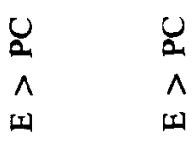

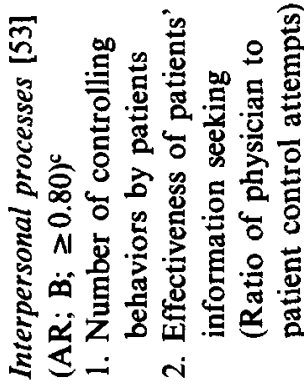

हैं

\section{尊高}

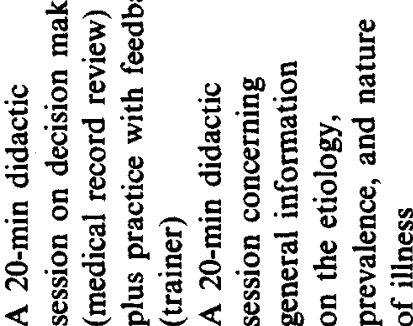

ए

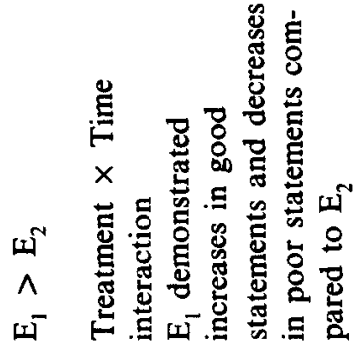

$\underset{\infty}{\infty}$

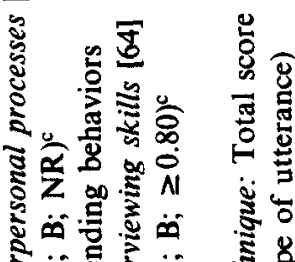

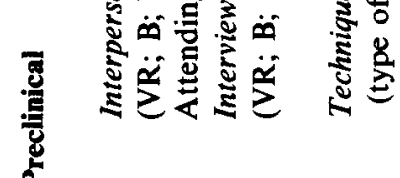

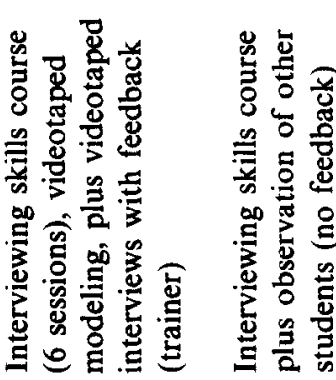

พิ
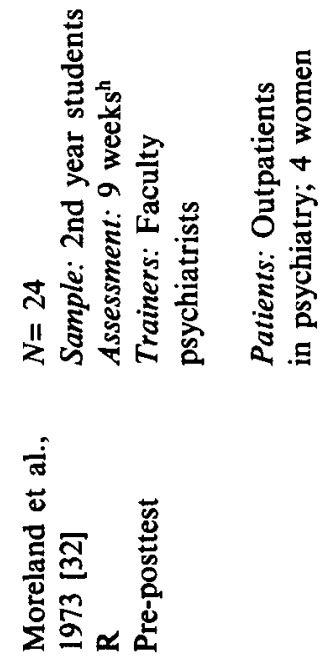

ज्

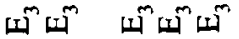

$\wedge \wedge \wedge \wedge \wedge$

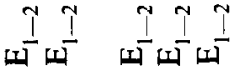

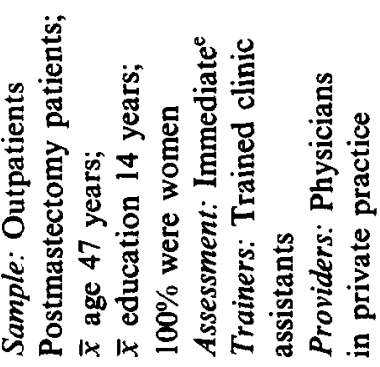

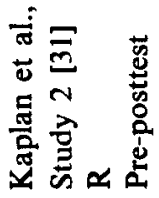

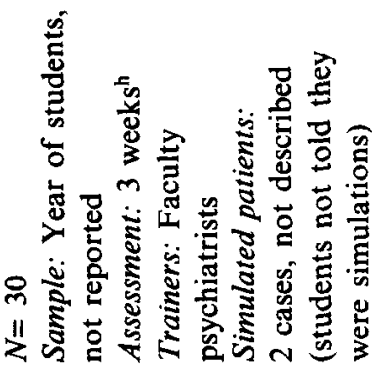

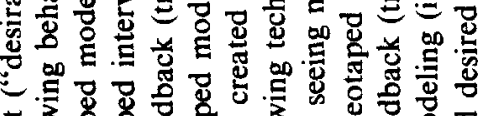

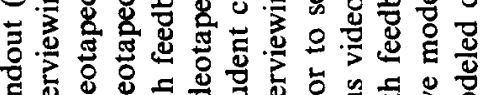

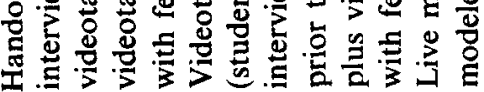

जั सึ का

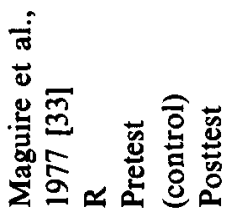




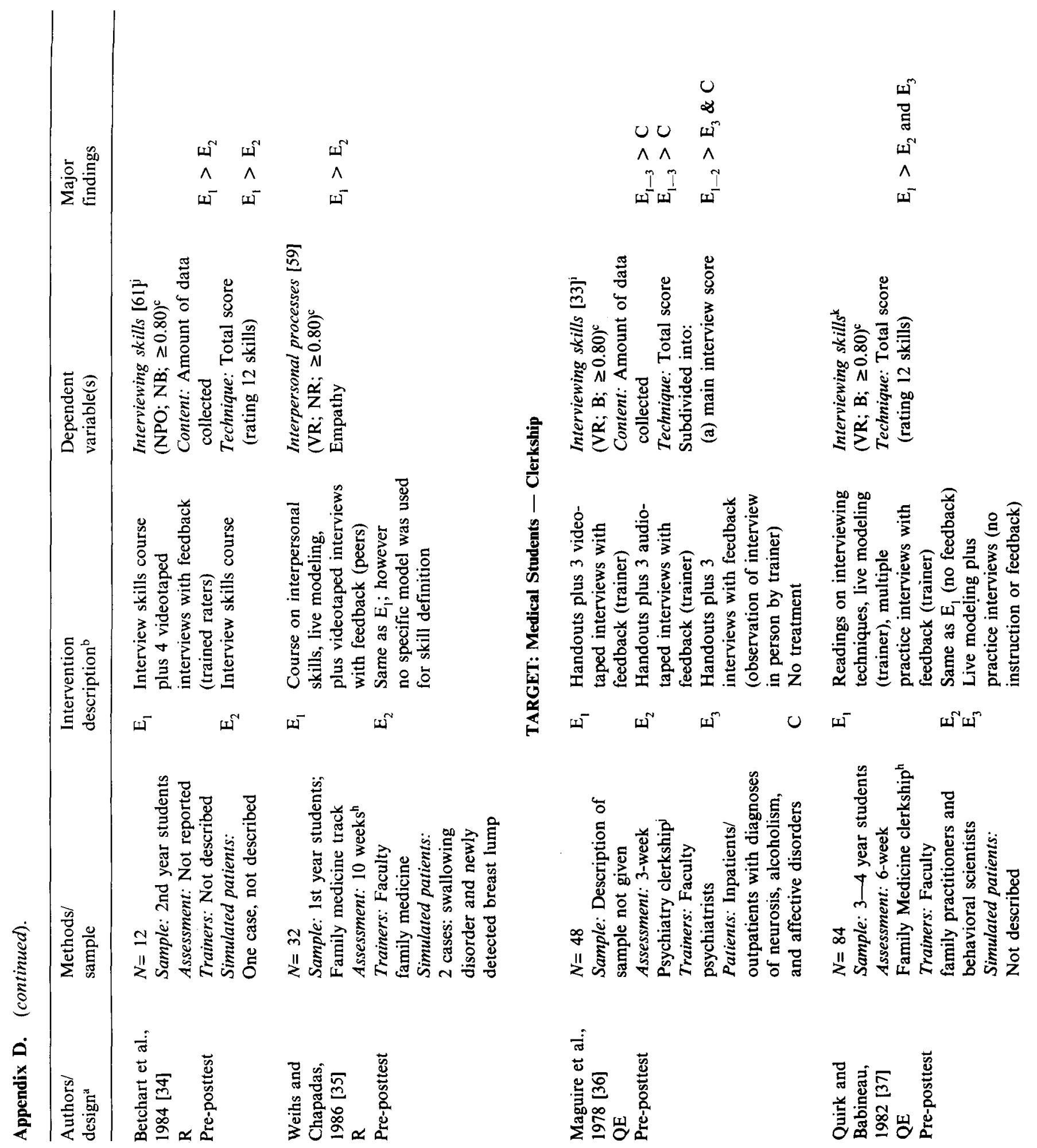




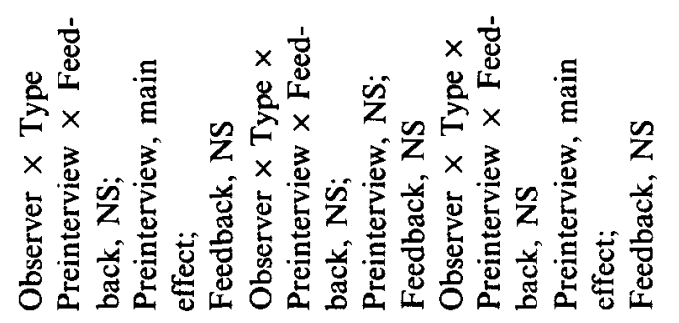

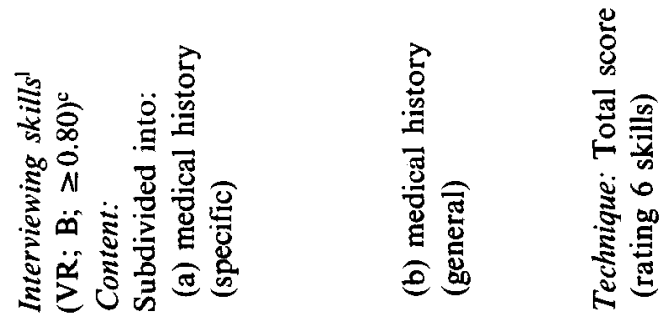

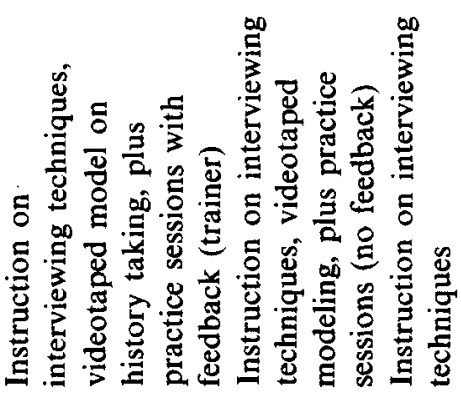

บ
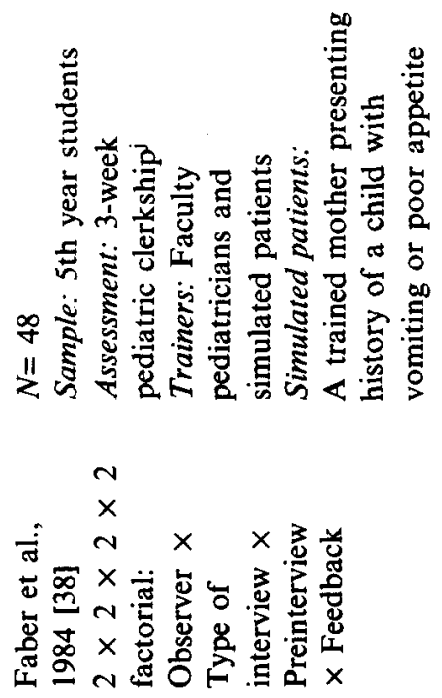
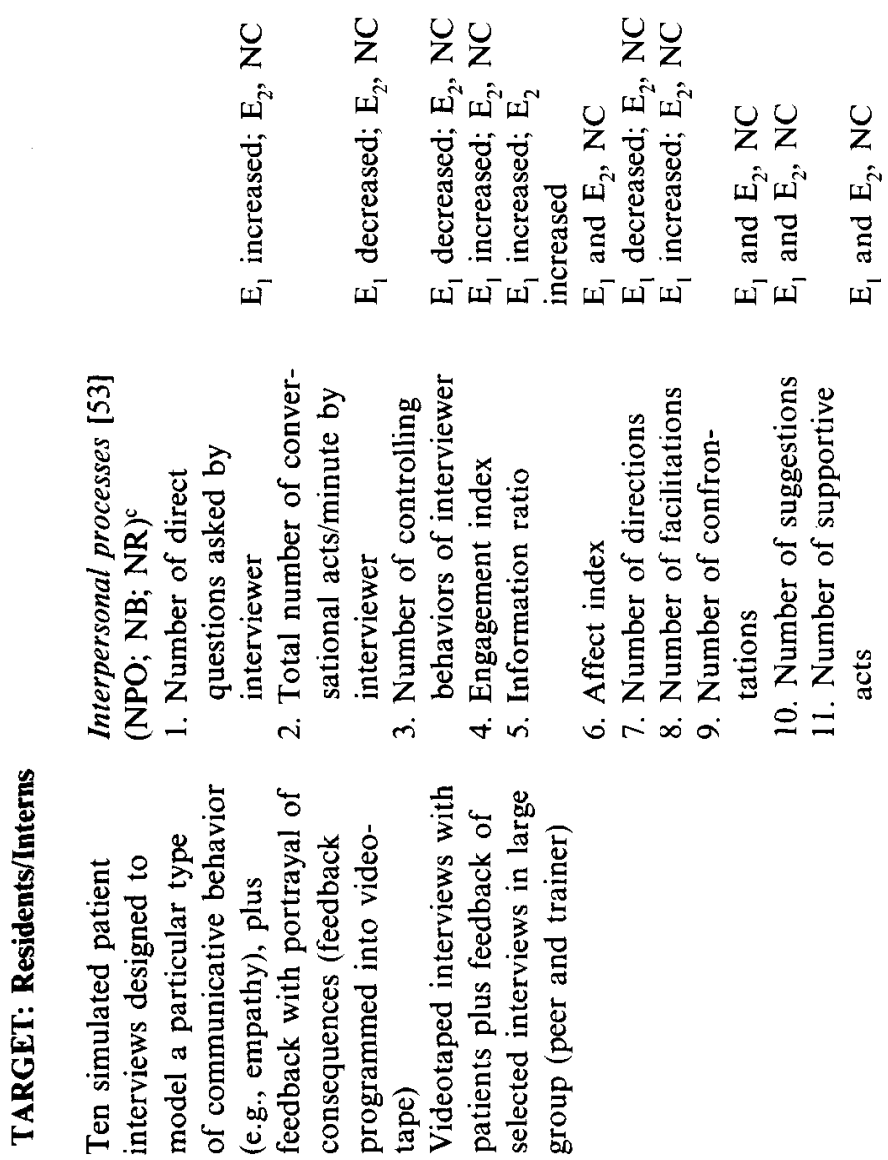

U్

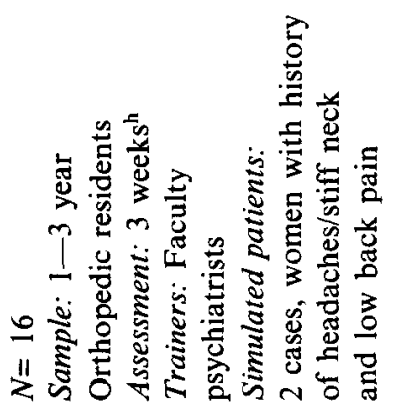

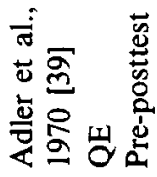




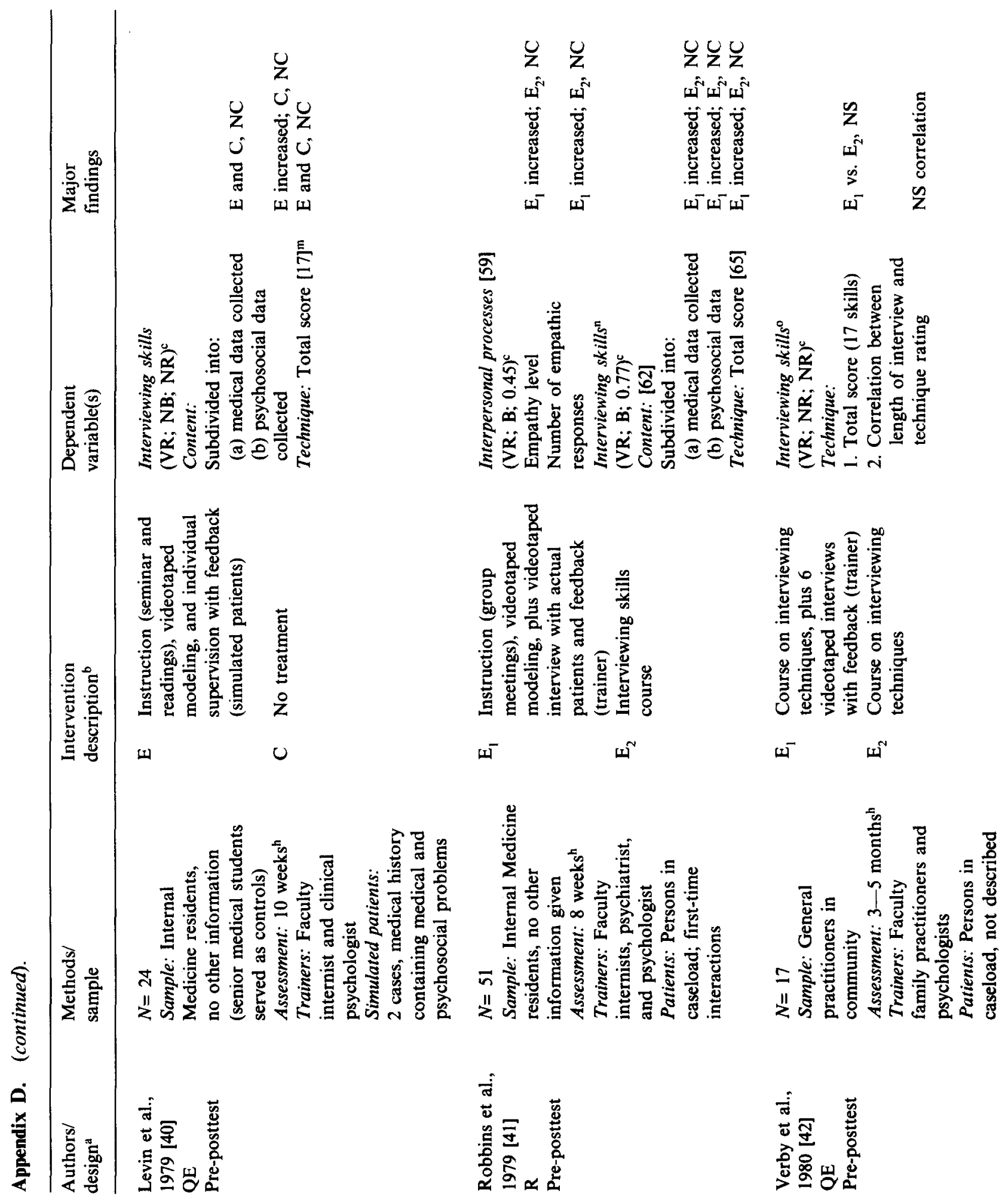




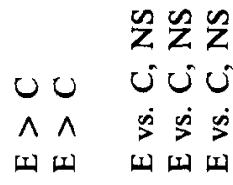

F

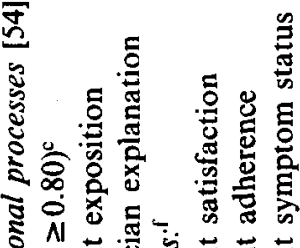

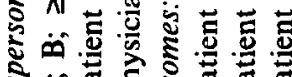

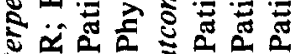

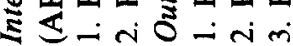

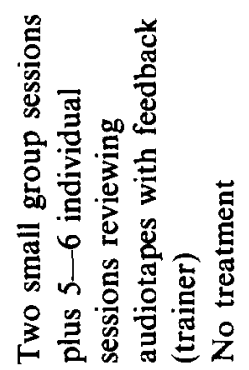

띠

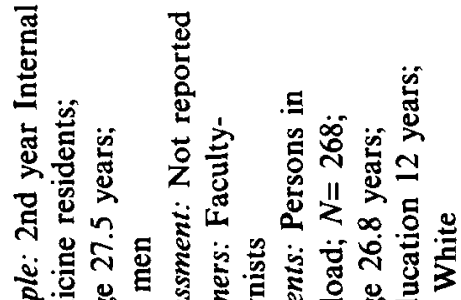

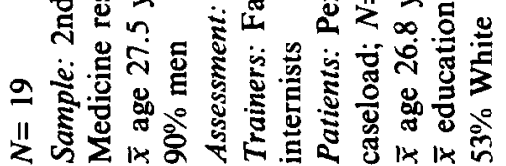

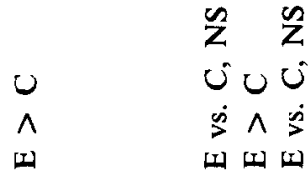

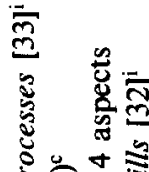

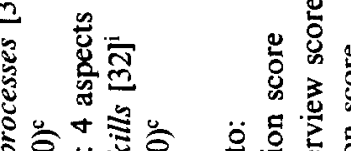

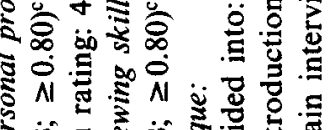

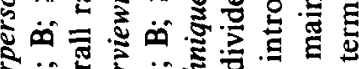

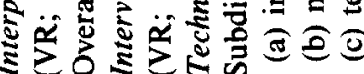

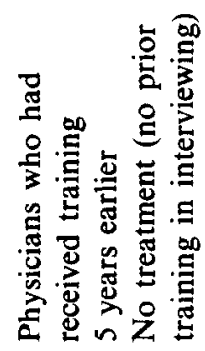

4 0
㔯告

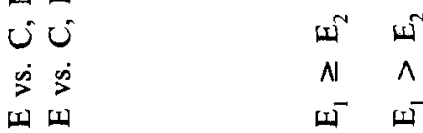




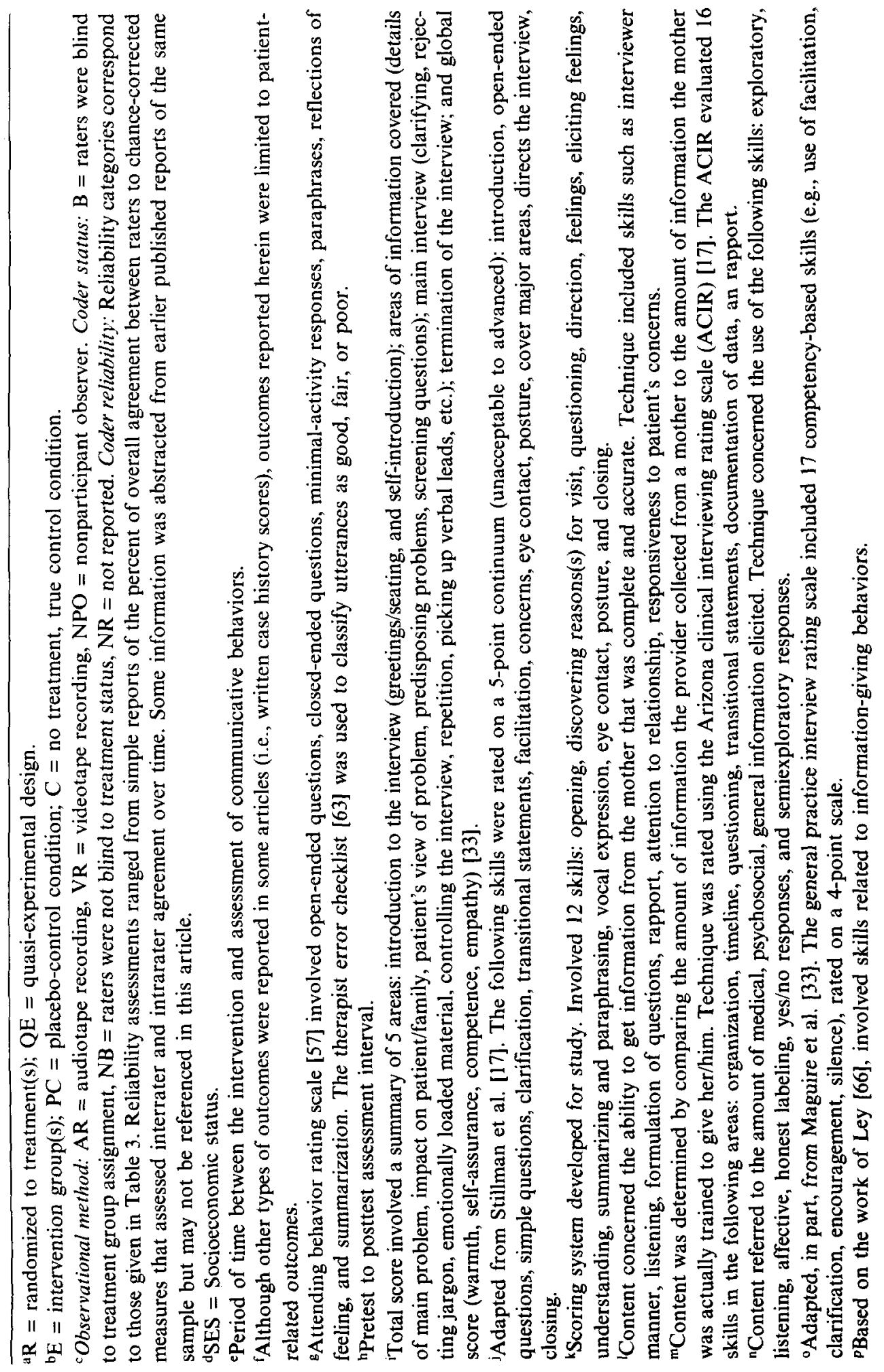

